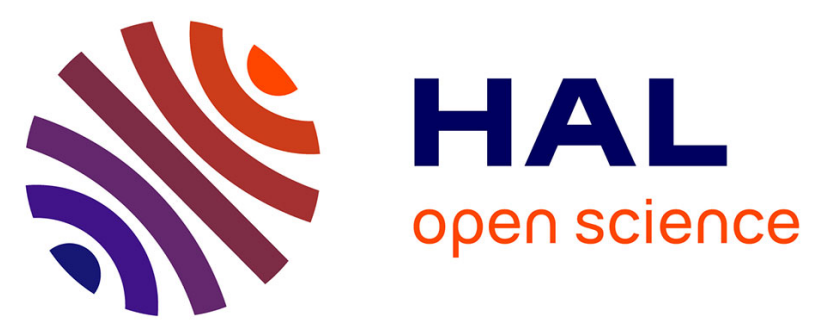

\title{
Crystal-Plastic Deformation in Seismically Active Carbonate Fault Rocks
}

\author{
Markus Ohl, Billy Clitton Nzogang, Alexandre Mussi, David Wallis, Martyn \\ Drury, Oliver Plümper
}

\section{To cite this version:}

Markus Ohl, Billy Clitton Nzogang, Alexandre Mussi, David Wallis, Martyn Drury, et al.. CrystalPlastic Deformation in Seismically Active Carbonate Fault Rocks. Journal of Geophysical Research : Solid Earth, 2021, 126 (4), pp.e2020JB020626. 10.1029/2020jb020626 . hal-03264843

\section{HAL Id: hal-03264843 \\ https://hal.univ-lille.fr/hal-03264843}

Submitted on 18 Jun 2021

HAL is a multi-disciplinary open access archive for the deposit and dissemination of scientific research documents, whether they are published or not. The documents may come from teaching and research institutions in France or abroad, or from public or private research centers.
L'archive ouverte pluridisciplinaire HAL, est destinée au dépôt et à la diffusion de documents scientifiques de niveau recherche, publiés ou non, émanant des établissements d'enseignement et de recherche français ou étrangers, des laboratoires publics ou privés.

\section{(c)(1)}

Distributed under a Creative Commons Attribution| 4.0 International License 


\section{JGR Solid Earth}

\section{RESEARCH ARTICLE \\ 10.1029/2020JB020626 \\ Key Points: \\ - Crystal-plastic deformation occurred in seismically deformed carbonate rocks \\ - Deformation and annealing produce a grain-boundary strengthening effect \\ - Repeated cyclic repetition of deformation and recrystallization leads to formation of a nanogranular material}

Supporting Information:

- Supporting Information S1

Correspondence to:

M. Ohl,

m.ohl@uu.nl

Citation:

Ohl, M., Nzogang, B., Mussi, A., Wallis, D., Drury, M., \& Plümper, O. (2021). Crystal-plastic deformation in seismically active carbonate fault rocks. Journal of Geophysical Research: Solid Earth, 126, e2020JB020626. https://doi. org/10.1029/2020JB020626

Received 17 JUL 2020 Accepted 22 JAN 2021 (c) 2021. The Authors.

This is an open access article under the terms of the Creative Commons Attribution License, which permits use, distribution and reproduction in any medium, provided the original work is properly cited.

\section{Crystal-Plastic Deformation in Seismically Active Carbonate Fault Rocks}

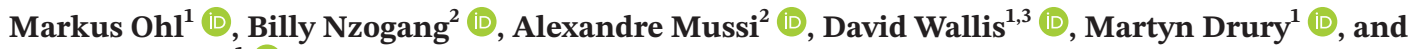 \\ Oliver Plümper ${ }^{1}$ (D)
}

${ }^{1}$ Department of Earth Sciences, Utrecht University, Utrecht, The Netherlands, ${ }^{2}$ Univ. Lille, CNRS, INRAE, ENSCL, UMR 8207-UMET—Unité Matériaux et Transformations, Lille, France, ${ }^{3}$ Now at Department of Earth Sciences, University of Cambridge, Cambridge, UK

\begin{abstract}
The spatial separation of macroscopic rheological behaviors has led to independent conceptual treatments of frictional failure, often referred to as brittle, and viscous deformation. Detailed microstructural investigations of naturally deformed carbonate rocks indicate that both frictional failure and viscous mechanisms might operate during seismic deformation of carbonates. Here, we investigate the deformation mechanisms that were active in two carbonate fault zones in Greece by performing detailed slip-system analyses on data from automated crystal-orientation mapping transmission electron microscopy and electron-backscatter diffraction. We combine the slip-system analyses with interpretations of nanostructures and predictions from deformation mechanism maps for calcite. The nanometric grains at the principal slip surface should deform by diffusion creep but the activation of the $(0001)<\overline{1} 2 \overline{1} 0>$ slip system is evidence for a contribution of crystal plasticity. A similar crystallographic preferred orientation appears in the cataclastic parts of the fault rocks despite exhibiting a larger grain size and a different fractal dimension, compared to the principal slip surface. The cataclastic region exhibits microstructures consistent with activation of the $(0001)<\overline{1} 2 \overline{1} 0>$ and $\{10 \overline{1} 4\}<\overline{2} 021>$ slip systems. Postdeformational, static recrystallization, and annealing produce an equilibrium microstructure with triple junctions and equant grain size. We propose that repeated introduction of plastic strain and recrystallization reduces the grain size and offers a mechanism to form a cohesive nanogranular material. This formation mechanism leads to a grain-boundary strengthening effect resulting in slip delocalization which is observed over 6 orders of magnitude $(\mu \mathrm{m}-\mathrm{m})$ and is expressed by multiple faults planes, suggesting cyclic repetition of deformation and annealing.
\end{abstract}

\section{Introduction}

Seismic slip and aseismic creep commonly occur in distinct portions of the lithosphere due to the different dependencies of the underlying deformation mechanisms on conditions such as pressure and temperature (Scholz, 1998). Frictional failure involves dilatant processes facilitated by low confining pressures at shallow depths (Sammis \& Ben-Zion, 2008; Sammis et al., 1987), whereas viscous deformation occurs by thermally activated processes promoted by higher temperatures at greater depths (Bürgmann \& Dresen, 2008; Sibson, 1982). However, the temperature increase through shear heating during seismic faulting (Rice, 2006) challenges this strict separation by potentially activating temperature-dependent deformation mechanisms, such as crystal plasticity and diffusion creep (Nielsen, 2017). Depending on the material, melting, or decomposition reactions can also occur at high temperatures, leading to severe microphysical changes that severely alter the mechanical behavior of faults (Di Toro et al., 2011; Niemeijer et al., 2012). The main factor limiting the operation of crystal plasticity in the brittle regime is the extremely short duration of the temperature increase during and after fault slip. Thermal models predict a temperature drop through thermal diffusion within one second after sliding ceases to a value similar to the background temperature (Demurtas et al., 2019; Di Toro \& Pennacchioni, 2004). Therefore, a key objective of earthquake geology is to assess the extent to which thermally activated processes impact fault structure and properties e.g., modifying the microstructure or activation of deformation mechanisms, during the short interval of coseismic slip.

Deformed carbonates from principal slip zones of natural and experimental faults commonly exhibit crystallographic preferred orientations (CPOs) (Delle Piane et al., 2017; Demurtas et al., 2019; Kim et al., 2018; Pozzi et al., 2019; Smith et al., 2013; Verberne et al., 2013). Most of the CPOs involve (0001) planes aligned 
subparallel to the shear plane, typically with an antithetic inclination against the shear direction. In addition, the CPOs include alignment of the $\langle\overline{1} 2 \overline{1} 0>$ axes subparallel to the shear direction. Similar CPOs are generated in high-temperature, low-strain rate experiments, in which calcite is deformed by dislocation-mediated deformation mechanisms (Pieri et al., 2001). In general, the observations of CPOs in carbonate fault rocks suggest that crystal plasticity contributes to accommodating applied strain during seismic deformation. The contrast between frictional failure at the macroscale and the formation of CPOs by dislocation-mediated processes at the microscale demonstrates the need to further constrain the spatial and temporal evolution of deformation mechanisms during fault slip.

At the microscale, high-temperature grain-boundary sliding (GBS) has been suggested to operate within the gouge volume near the principal slip surface (PSS) (De Paola et al., 2015). In the pursuit of predicting rheological behavior during seismic fault slip, De Paola et al. (2015) used deformation mechanism maps constructed from steady-state flow laws. For carbonates with small grain sizes, these flow laws predict the operation of grain-size sensitive (GSS) deformation mechanisms such as diffusion creep (Herwegh et al., 2003) and dislocation-accommodated grain-boundary sliding (disGBS) (Walker et al., 1990). In contrast, coarsegrained carbonates are predicted to exhibit grain-size insensitive (GSI) behavior inferred to result from dislocation glide and dislocation cross-slip (De Bresser, 2002; Renner et al., 2002). To reasonably use flow laws to predict rheological behavior, flow-law parameters, such as the stress exponent, $n$, the grain-size exponent, $p$, and the activation energy, $Q$, must be known. Most of the parameters are derived from laboratory experiments under well-constrained conditions and at steady state so that inferring these parameters for the materials in any particular natural fault zone can be challenging. Strain rates during experiments performed to constrain flow-law parameters are orders of magnitude lower than those occurring during seismic slip on natural faults and therefore, predicting deformation mechanisms during seismic deformation requires the flow laws to be extrapolated in stress/strain rate. It is challenging to test the accuracy of such extrapolations based on mechanical data from high-velocity deformation experiments, so microstructural analyses offer critical additional information against which to test the accuracy of flow-law predictions.

The present study continues previous work on the nanostructural processes of the same fault exposures. For more information and a detailed introduction to the geological background the reader is kindly referred to Ohl et al. (2020). In the present study, we characterize the microstructure and nanostructure of natural carbonate fault rocks directly at a slip interface using multiscale crystallographic orientation analyses to evaluate deformation mechanisms during seismic events. The fault-rock microstructures reveal that crystal plasticity contributed during deformation and that the microstructure was potentially modified by recrystallization.

\section{Geology and Tectonic Setting}

The first investigated fault exposure $\left(38^{\circ} 43^{\prime} 56.17^{\prime \prime} \mathrm{N}, 23^{\circ} 0^{\prime} 27.41^{\prime \prime} \mathrm{E}\right)$ is located close to Arkitsa, along the northern coast of the Gulf of Evia, Greece. This fault exposure is part of the Kamena Vourla fault system with a length of about 30-40 km (Ambraseys \& Jackson, 1990). In general, the ESE-WNW-striking, N-dipping fault planes separate Triassic to Middle/Late Jurassic platform carbonates of the footwall from lower Pliocene-Pleistocene up to Quaternary hanging-wall sediments (Kokkalas et al., 2007). The footwall cataclasite is a grayish, matrix-supported fault rock with host-rock clasts (Figures 1a, S1a and S1b). Multiple fault planes are hosted inside the damage zone, indicating fault-plane overstepping (Figure 1b). Cumulative fault displacement is not mentioned or documented in the geological literature, but present days outcrop situation shows the fault rocks in contact with quaternary deposits. Records of historic seismicity document $\sim 13$ events since 426 BCE with the last major nearby event of $M_{\mathrm{s}} 6.9$ in 1894 (Ambraseys \& Jackson, 1990).

The second fault exposure $\left(38^{\circ} 2^{\prime} 14.40^{\prime \prime} \mathrm{N}, 2^{\circ} 0^{\prime} 22.33^{\prime \prime} \mathrm{E}\right)$ is located close to Schinos, Corinth area. Here, the fault exposure is part of a $\sim 25-\mathrm{km}$ long onshore fault line with an E-W strike, dipping toward N. The host rocks are Upper Triassic limestones and dolomites (Kaplanis et al., 2013) and a reddish cataclasite with light-gray host-rock clasts forms the footwall fault rock (Figures 1c, S1c, and S1d). In the field, the faultplane exposure shows at least one stepover (Figure 1d). Cumulative fault displacement is not mentioned or documented in the geological literature, but present days outcrop situation shows the fault rocks in contact 


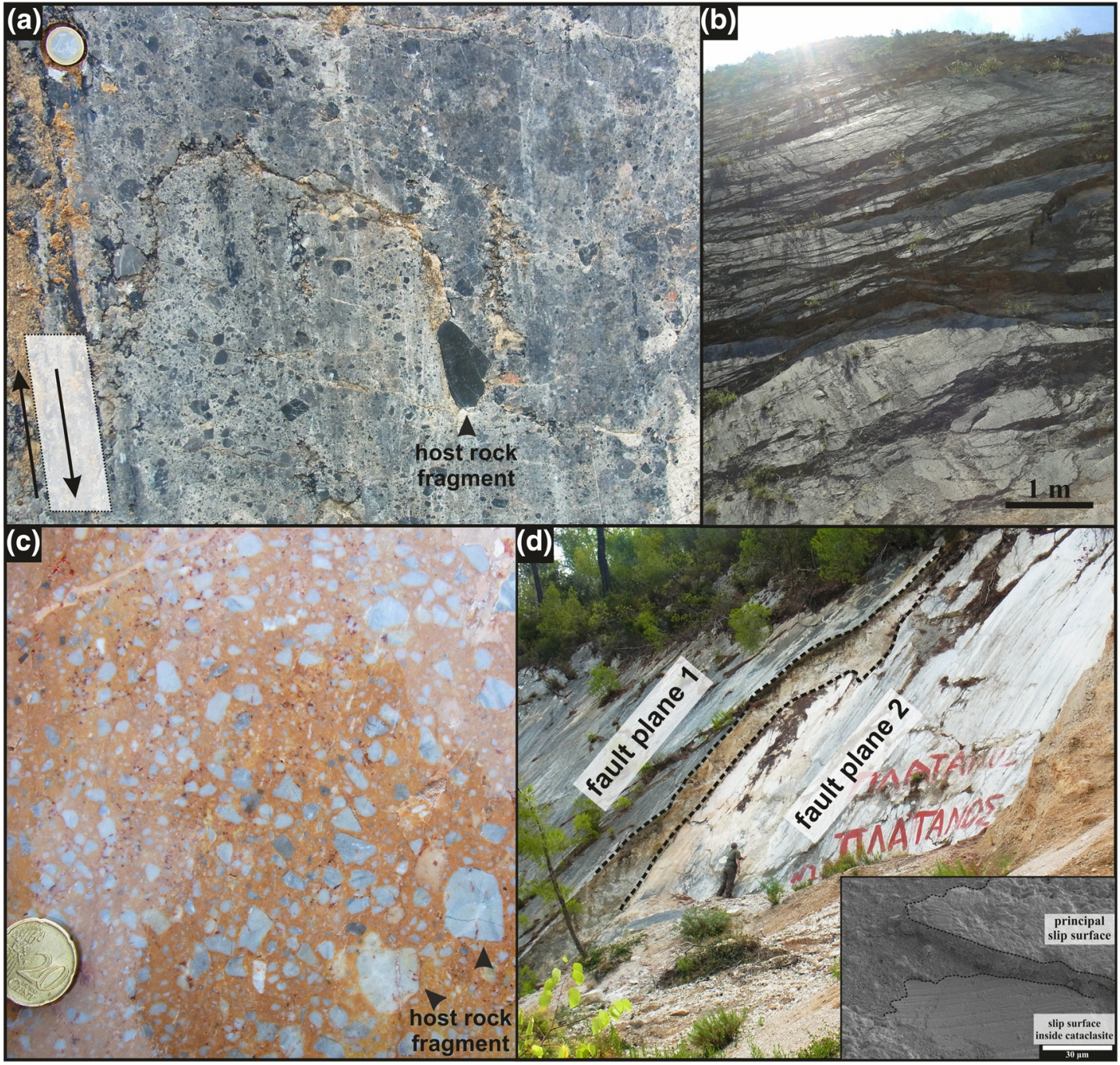

Figure 1. Overview of geological features. (a) View onto Arkitsa fault plane. Dark, large host-rock clasts are incorporated into the light-gray footwall cataclasite. Sketch indicates slip direction. One-Euro coin for scale. (b) Multiple slip planes hosted inside the damage zone of the Arkitsa fault exposure exhibit overstepping. (c) View onto Schinos fault plane. Light-gray host-rock clasts incorporated into red hanging-wall cataclasite. (d) Field view of Schinos fault-plane exposure. Two distinct and overstepping fault planes are visible, hosted inside the damage zone. Person for scale. Inset: Secondary electron image showing development of secondary slip surface inside the Schinos footwall cataclasite. The secondary slip surface is situated about $10 \mu \mathrm{m}$ below the principal slip surface.

with quaternary colluvium deposits. The last seismic event in the region was recorded in February 1981, when three major events occurred with a maximum magnitude of $M_{\mathrm{s}} 6.7$ (Collier et al., 1998).

Subduction-related back-arc volcanism, combined with extensional tectonics caused by rollback of the Hellenic subduction zone (Thomson et al., 1998), results in a high geothermal gradient across the Aegean region (Lambrakis et al., 2014; Papachristou et al., 2014). The geothermal gradient measured from geothermal exploration boreholes in the Sperchios basin, $\sim 50 \mathrm{~km}$ west of Arkitsa, is $35^{\circ} \mathrm{C} / 100 \mathrm{~m}$ (Metaxas et al., 2010). Similar measurements at Kamena Vourla indicate $46^{\circ} \mathrm{C}$ at $200 \mathrm{~m}$ depth (Mendrinos et al., 2010). Clay-mineral assemblages in the Arkitsa fault formed from 100 to $150{ }^{\circ} \mathrm{C}$ (Papoulis et al., 2013). However, the clays are found inside the hanging-wall breccia and may not reflect the processes and temperatures on the fault plane. Also, in the Sousaki-Loutraki region close to Schinos, geothermal exploration drilling revealed high temperatures at shallow depth. In this region, (Mendrinos et al., 2010) measured $63{ }^{\circ} \mathrm{C}$ at $500-1,100 \mathrm{~m}$ depth, which is in agreement with (Lambrakis et al., 2014) obtaining $\geq 75^{\circ} \mathrm{C}$ at $600-900 \mathrm{~m}$ depth. Because the above-mentioned temperature indications stem from geothermal explorations, it is not clear whether 
they represent temperatures of host rock or fluid temperatures. However, thermal models of the Aegean region predict temperatures from $200{ }^{\circ} \mathrm{C}$ (Limberger et al., 2014) to $360{ }^{\circ} \mathrm{C}$ (Larède, 2018) at $5 \mathrm{~km}$ depth.

\section{Methods}

\subsection{Crystal-Orientation Acquisition}

Thin sections were prepared from drill cores by cutting parallel to the slip direction and normal to the slip surface. Electron-backscatter diffraction (EBSD) data were acquired using a Philips XL30 scanning electron microscope (SEM) equipped with an Oxford Instruments Nordlys 2 CCD camera. Maps were acquired with an accelerating voltage of $30 \mathrm{kV}$, probe current of $9.5 \mathrm{nA}$, and step size of $0.5 \mu \mathrm{m}$ for the Arkitsa sample and $20 \mathrm{kV}$ accelerating voltage, $9.5 \mathrm{nA}$ probe current, $0.7 \mu \mathrm{m}$ step size for the Schinos sample.

Crystal-orientation data were also acquired in a scanning-transmission electron microscope (STEM) using the automatic crystal-orientation mapping technique (ACOM-TEM, Rauch \& Véron, 2014). TEM foils were prepared with an FEI Helios G3 focused ion-beam scanning electron microscope (FIB-SEM). ACOM-TEM data were acquired using the NanoMEGAS ASTAR/SPINSTAR system on a FEI Tecnai $\mathrm{G}^{2}-20$ twin. Beam conditions during ACOM-TEM were $200 \mathrm{kV}$ and spot size 11, giving a nominal 1-nm probe diameter, resulting in a step size of $2 \mathrm{~nm}$. During acquisition, the primary electron beam was set to precession movement, with an opening angle of $0.5^{\circ}$. In a separate step, the acquired electron diffraction patterns were matched with a precalculated bank file containing the simulated crystal orientations in kinematic conditions, resulting in a unique crystal-orientation solution.

\subsection{Data Treatment}

Orientation data from EBSD and ACOM-TEM were processed using the MTEX 4.5.2 toolbox (Bachmann et al., 2011; Hielscher \& Schaeben, 2008). The reference frame was set to $x$-axis to the east, $y$-axis to the south, and $z$-axis out of plane. Grain boundaries were defined as misorientation angles $>10^{\circ}$ and subgrain boundaries were defined as misorientation angles in the range $1-10^{\circ}$ for ESBD and $2-10^{\circ}$ for ACOM-TEM. Unindexed pixels or single pixels matched as a different phase were removed and unindexed pixels were filled with the average orientation of their grain neighbors. Grains $<5$ pixels were removed from EBSD data sets. Grains and subgrains $<20$ pixels were removed from the ACOM-TEM data set. A Kuwahara filter with a kernel size of $5 \times 5$ was applied to the ACOM data set to reduce orientation noise. All crystal-orientation plots were visualized before denoising to guard against the introduction of artifacts. Contoured pole figures are based on one-point-pergrain orientation data. The optimum half-width for contoured EBSD pole figures was estimated using the De la Vallée Poussin kernel approach. Because this estimation was inconsistent with the low estimated optimum half-width for the ACOM-TEM data, we chose $15^{\circ}$ to match the EBSD pole figures. Misorientation inverse pole figures (MIPF) were plotted for subgrain-boundary misorientation angles of $1-10^{\circ}$ for EBSD and $2-10^{\circ}$ for ACOM-TEM.

\subsection{Grain-Size Analysis}

A grain-size distribution was determined from the EBSD and ACOM-TEM data. The ACOM-TEM grainsize distribution was based on a grain-boundary trace map by combining a reliability map and an indexed crystal-orientation map. In order to ensure comparability of EBSD and ACOM-TEM data fractal-dimension analysis, the calculated grain-size frequencies from the ACOM-TEM data were scaled with the difference in area resolution, due to differences in step size, by a factor of 62,500. In this procedure, a $500 \times 500 \mathrm{~nm}$ pixel (EBSD) was divided by a $2 \times 2 \mathrm{~nm}$ pixel (ACOM-TEM) which equates to the factor of 62,500 . To obtain a grain-size distribution, we chose the data set binning to be continuous, e.g., equal to the mapping step size, to reduce undersampling of small grains. Each data set was individually fitted with a linear equation where the negative slope of the linear fit in log-log space equals the fractal dimension $D$. The grain-size bin width for the fractal-dimension plot was set to $1 \mu \mathrm{m}$ to adequately subdivide for the large number of small grains. 


\section{Results}

\subsection{Microscale Crystal-Orientation Data}

Figure 2a presents the EBSD map of the Arkitsa footwall cataclasite. The map exhibits small matrix-forming grains and larger host-rock clasts, where the clasts show an internal fine-grained foam microstructure. The fine-grained matrix and the foam microstructure display straight grain boundaries that meet in $120^{\circ}$ triple junctions (Figures 2c and 2a). Grain boundaries are typically not aligned over distances greater than one grain diameter. Monocrystalline calcite clasts occasionally host twin lamellae. An elongated host-rock grain at the top left of Figure 3a exhibits a gradual increase of small grains from a monocrystalline to a polycrystalline calcite clast. The median grain size is $5.0 \mu \mathrm{m}$ (Figure 2b). MIPFs for each subset in Figure 2a reveal concentrations of misorientation axes approximately centered on [0001]. The pole figures of (0001) and $<\overline{1} 2 \overline{1} 0>$ (Figure $2 \mathrm{~d}$ ) display a weak CPO with multiples of uniform distribution (MUD) in the range 0.8-1.2. The (0001) planes are parallel to the slip plane and the $<\overline{1} 2 \overline{1} 0>$ axes are parallel to the slip direction (noting the orientation of the trace of the slip surface at the top right of Figure 2a). The subgrain-boundary MIPF for the overall map data exhibits a cluster of misorientation axes parallel to [0001] (Figure 2e), like the individual subsets in Figure 2a.

Figure 3a presents the EBSD results from the Schinos footwall cataclasite. The band-contrast map reveals a microstructure with large calcite host-rock grains incorporated into the cataclasite matrix. Like Figure 2a, several host-rock grains exhibit an increase of small grains from monocrystalline to polycrystalline (Figure 3c). While many grain boundaries are curved, several in both, the matrix and host-rock grains are straight and meet in $120^{\circ}$ triple junctions (Figure 3c, white circles). The outer margins of the host-rock grains display a rim with grain boundaries, creating an incipient core-mantle structure (Figure $3 \mathrm{c}$ ). The median grain size is $4.4 \mu \mathrm{m}$ (Figure 3b). The pole figures in Figure 3d display a weak CPO with multiples of uniform distribution (MUD) in the range 0.8-1.2. The (0001) planes are parallel to the slip plane and the $<\overline{1} 2 \overline{1} 0>$ axes are parallel to the slip direction. Furthermore, $\{10 \overline{1} 4\}$ poles exhibit a weak cluster approximately parallel to the slip-plane normal and the $<\overline{2} 021>$ axes exhibit three maxima subperpendicular to the slip plane. In addition, $\{\overline{1} 012\}$ planes exhibit one maximum and a girdle, whereas $<10 \overline{1} 1>$ directions are oriented perpendicular to the slip plane. MIPFs for subgrain-boundary misorientation axes in each vertical section in Figure 3a exhibit a pronounced maximum centered on the $<\mathrm{a}>$ direction. Secondary maxima are centered on $\langle\mathrm{m}>,<\mathrm{c}>$, or $<\mathrm{a}>$, or a combination of all three directions. The overall MIPF in Figure $3 \mathrm{e}$ exhibits subgrain misorientation axes predominantly around $<\mathrm{a}>$, consistent with most misorientation axes in the vertical sections from Figure 3a.

\subsection{Nanostructures}

TEM investigation of the Arkitsa fault rock also reveals a fine-grained volume situated on top of coarser grains (Figure 4a). The first 15-20 $\mu \mathrm{m}$ of material directly below the PSS exhibits a foam nanostructure. This foam nanostructure consists of grains with approximately equal grain size and straight grain boundaries that meet in triple junctions with $120^{\circ}$ angles (Figure $4 \mathrm{c}$ ). The grains in this zone are commonly sandwiched between, and overprinted by, microstructural discontinuities (e.g., Figure 4c, white lines) dipping at an angle of about $30^{\circ}$ to the slip surface into the nanogranular material. The discontinuities can displace single grains (Figures $4 \mathrm{~b}$ and $4 \mathrm{c}$ ) or form bands of localized deformation with a sigmoidal appearance, preserving the intact foam nanostructure in between (Figures $4 b$ and $4 d$ ). In Figure 4c, grains with similar diffraction contrast are displaced about $220 \mathrm{~nm}$ along such microstructural discontinuities. These discontinuities cannot be traced to the slip surface (Figure 4c) but terminate in an area with a smaller grain of $\sim 50 \mathrm{~nm}$ size below the PSS (Figure 4c) compared to $300 \mathrm{~nm}$ further away from the PSS (Figure 6, grain No. 3). Larger grains are occasionally intermingled with the nanogranular material (Figure 4a). Below the nanogranular material, twinned calcite grains of 3-5 $\mu \mathrm{m}$ in diameter mark the beginning of the cataclasite (Figure 4a). The grain size at the transition between the slip-surface nanostructure and the larger grains corresponds to the grain sizes observed in the EBSD map (Figures 4a and 4d).

Figures $5 \mathrm{a}$ and $5 \mathrm{~b}$ present the nanostructure of the Schinos fault directly at the PSS. Compared to the Arkitsa sample (Figures 4a and 4c), the grain size is larger, resulting in a less complex nanostructure. The Schinos nanostructure exhibits a straight grain-boundary morphology with triple junctions (Fig- 

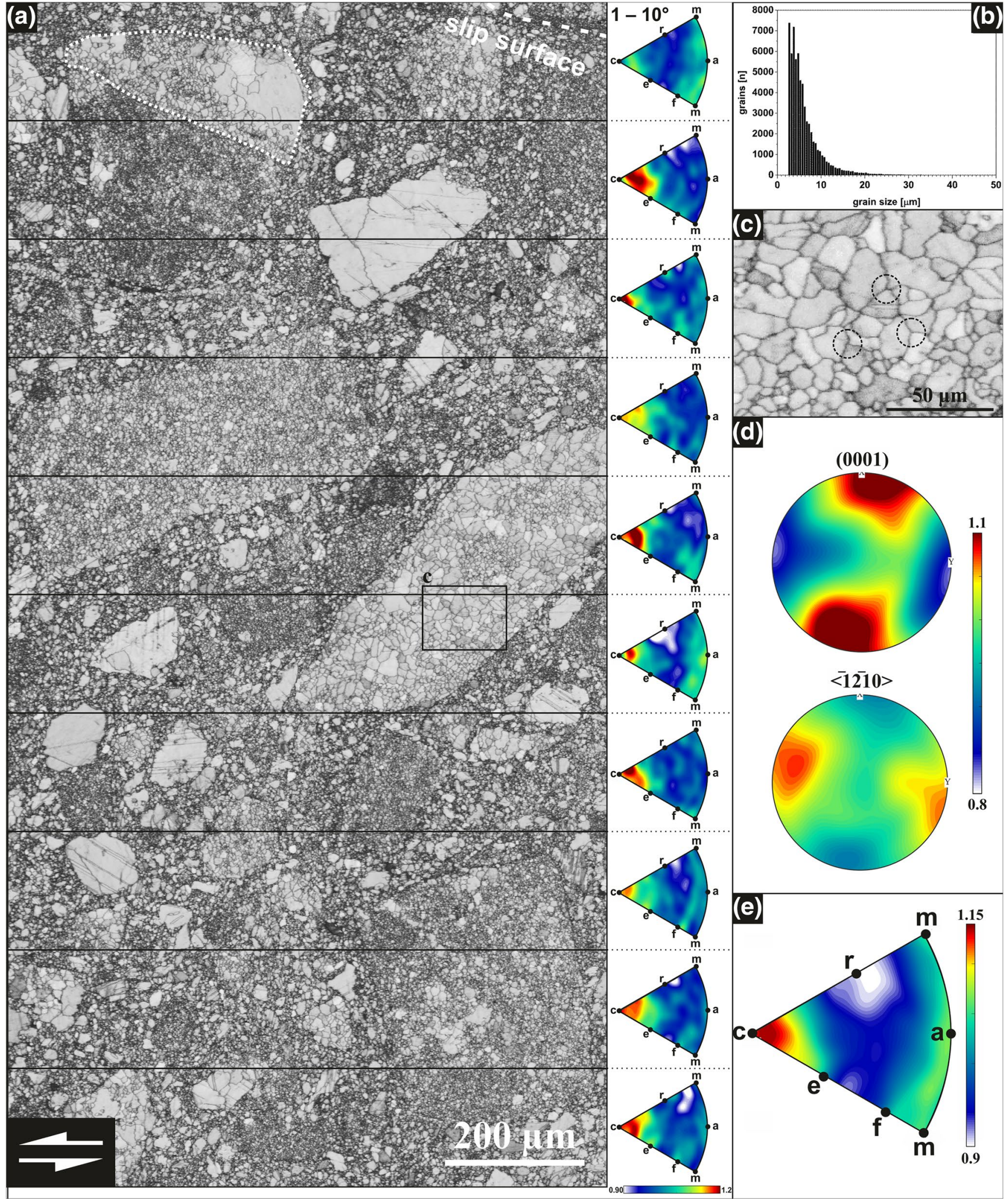

Figure 2. Electron-backscatter diffraction results of the Arkitsa fault-exposure cataclasite. (a) Band-contrast map and MIPF for each subsection. Fault surface with hanging-wall in top-right corner. (b) Grain-size distribution. $n_{\text {total }}=78,143$. (c) Detailed view of host-rock clast microstructure. Black circles mark triple junctions and $120^{\circ}$ angles. (d) Pole plots of (0001) planes and $<12 \overline{1} 0>$ axes in the same reference frame as the map in (a). (e) MIPF of the full map area. Labels indicate crystal directions or plane normals. Contours are multiples of uniform distribution. MIPF, misorientation inverse pole figures. 

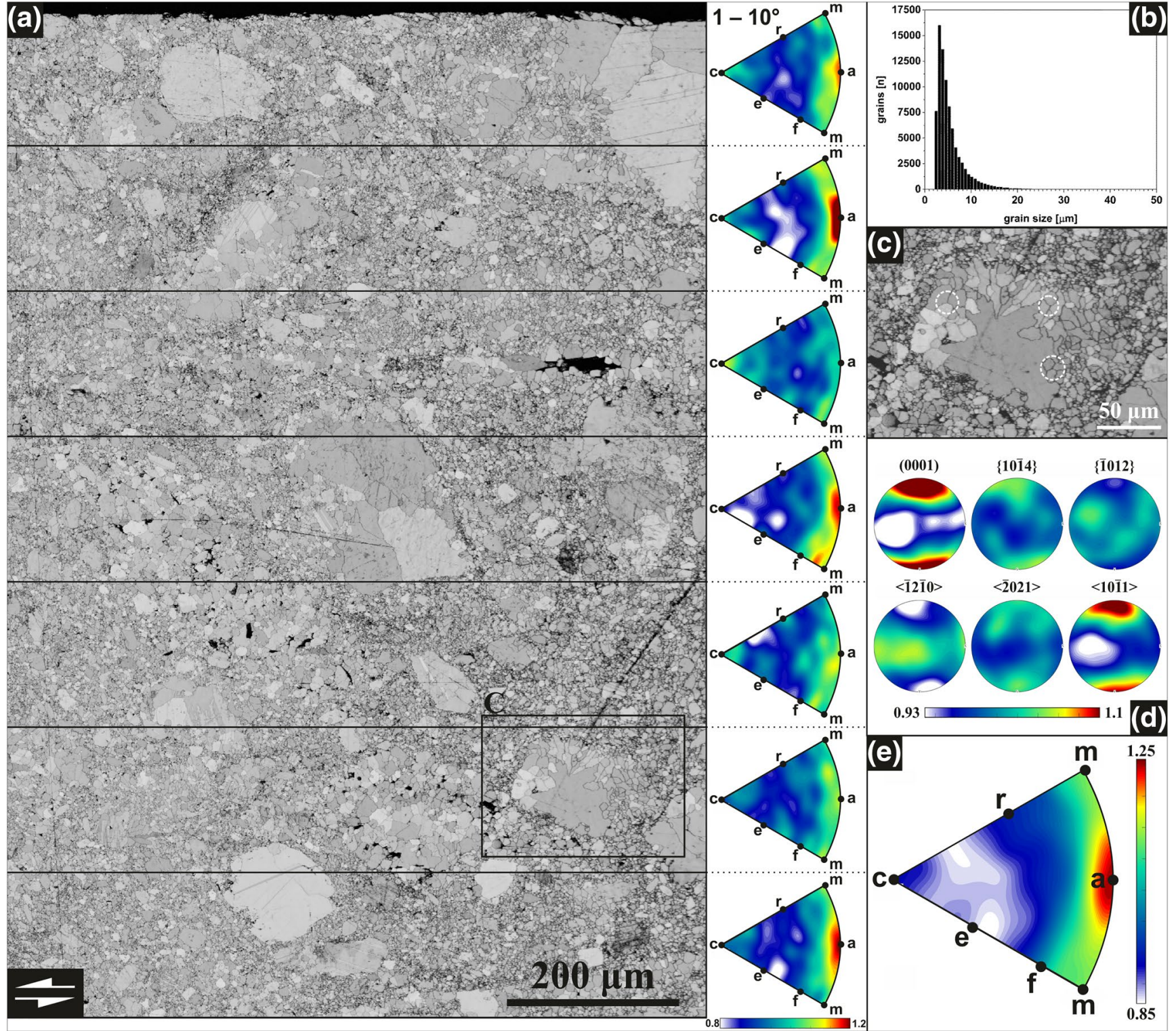

Figure 3. Electron-backscatter diffraction results of the Schinos fault-exposure cataclasite. (a) Band-contrast map and MIPF for each subsection. Fault surface at the top (black). (b) Grain-size distribution. $n_{\text {total }}=90,803$. (c) Clast in matrix displaying a mantle of grains around a host-rock clast with internal triple junctions (white dashed circle). (d) Combined pole plots of relevant slip systems from (a). (e) Misorientation inverse pole figure from the full data set in (a). MIPF, misorientation inverse pole figures.

ure 5a) and subgrain boundaries (Figure 5b). The average dislocation density in the larger Schinos grains is $\sim 1.5 \times 10^{13} \mathrm{~m}^{-2}$. The dislocation density decreases toward the subgrain boundaries but otherwise the distribution is generally homogeneous except for some subgrain interiors that are devoid of dislocations (Figure 5b).

\subsection{Nanoscale Crystal-Orientation (ACOM-TEM)}

Figure 6 presents the ACOM-TEM data acquired on a subset of the same FIB foil shown in Figure 4c, reproducing the bright-field (BF) TEM nanostructure (Figures 4c, 6a, and 6b). Pole figures constructed from the crystal-orientation map exhibit a CPO with (0001) plane-normal densities in the range 0.4-2.0 MUD in the highly deformed, fine-grained region below the PSS. Some grains exhibit an orientation spread indicating intragranular misorientation (Figure 6b). The median grain size is $21 \mathrm{~nm}$ (Figure 6c), albeit ranging between 


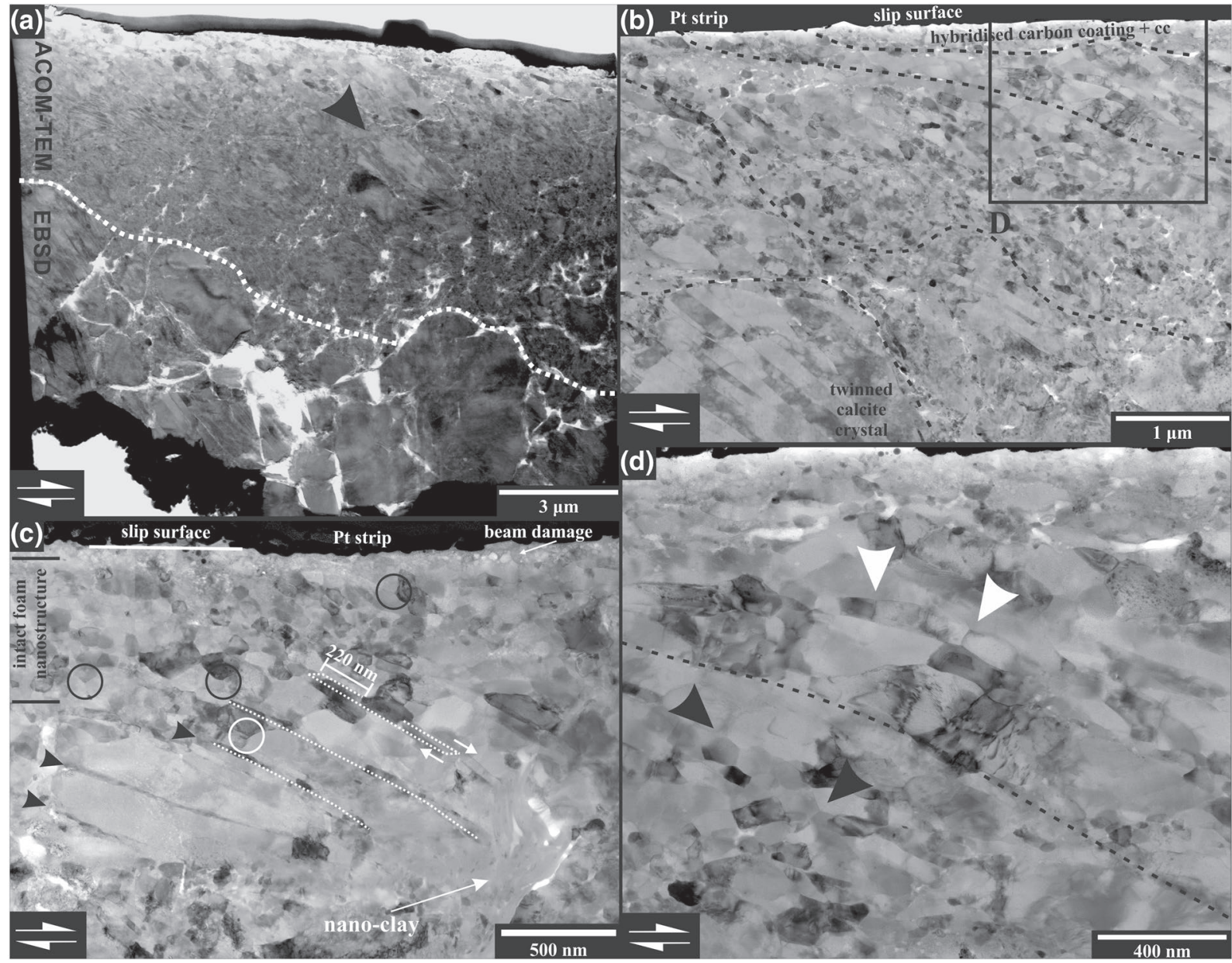

Figure 4. Arkitsa fault-exposure nanostructures. (a) Bright-field (BF) TEM overview of deformed volume with a sharp boundary to the footwall cataclasite (dashed line). Larger grains show strong deformation (black arrow). The grain size of the less deformed grains is about 3-5 $\mu \mathrm{m}$. (b) Bright-field STEM image with detailed view of the deformed volume. Anastomosing boundaries separate alternating domains of deformed and intact foam nanostructure (black dashed lines). (c) Bright-field STEM image showing intact foam nanostructure with triple junctions and $120^{\circ}$ angles adjacent to the slip surface (black circles). Fractures that dissect grains terminate inside intact foam nanostructure. Fractures appear to evolve from former cleavage planes (black arrows). Older foam nanostructure is preserved between fracture planes (white circle). (d) Bright-field STEM image of detailed view from (b) Deformed foam nanostructure with former triple junctions while having a sheet-like structure (white arrows) next to intact foam nanostructure (black arrows).

5 and $300 \mathrm{~nm}$. Contoured pole figures (Figure 6c) reveal a CPO with [0001] axes oriented perpendicular to the slip surface and $\langle\overline{1} 2 \overline{1} 0>$ axes clustered subparallel to slip direction. A second clustering of $\langle\overline{1} 2 \overline{1} 0>$ axes appear as a ring around the center of the pole figure. The MIPF of the subgrain misorientation axes exhibits maxima parallel to [c] and $<\mathrm{m}>$.

\subsection{Grain-Size Distribution}

Figure 7 presents a log-log plot of relative frequency as a function of grain size from the EBSD and ACOM-TEM data. A data gap between $350 \mathrm{~nm}$ and $2 \mu \mathrm{m}$ arises from the different spatial resolutions and area coverage of the two techniques. The EBSD-based fractal dimension of the Arkitsa fault exposure is $D=2.887\left(R^{2}=0.912\right)$, while the fractal dimension of the ACOM-TEM data is $D=1.574\left(R^{2}=0.895\right)$. The EBSD-based fractal dimension of the Schinos sample is $D=2.833\left(R^{2}=0.902\right)$. Extrapolations of the grain-size distributions measured from the two different image data sets intersect at a grain size of $\sim 1 \mu \mathrm{m}$. 


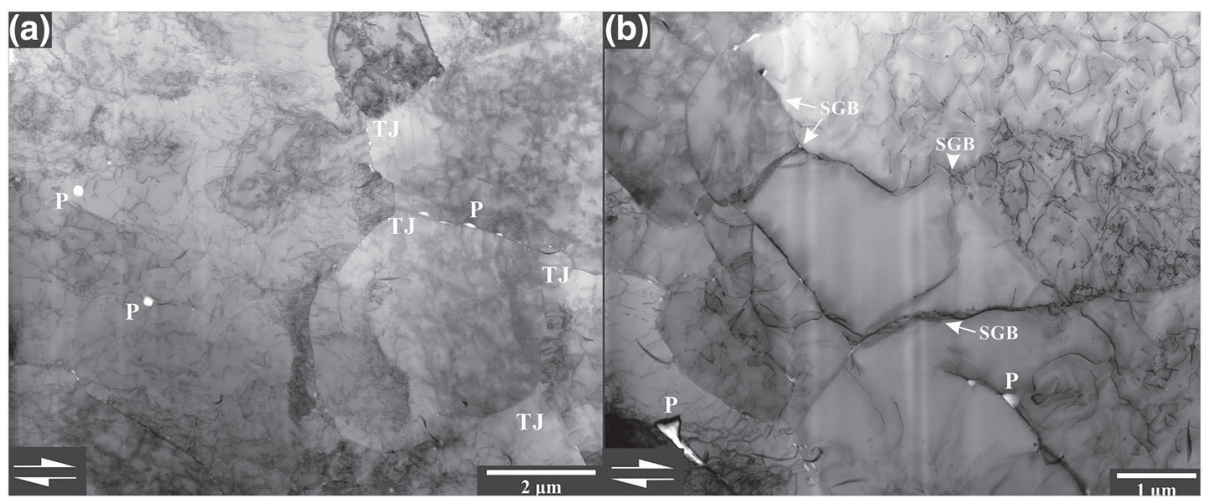

Figure 5. Schinos fault-exposure nanostructures. (a) BF-STEM image with overview of dislocation structure showing triple junctions (TJ) and grains with dislocation densities of $1.5 \times 10^{13} \mathrm{~m}^{-2}$ and higher. (b) BF-STEM image with dislocation-free subgrain in the center surrounded by subgrain boundaries (SGB). Dislocation density of surrounding grain interiors decreases toward the SGB. P, pores.

\section{Discussion}

\subsection{Grain Fragmentation and Fractal Dimensions}

Brecciation and cataclasis are important mechanisms of grain-size reduction in fault zones. Whereas intragranular extensional fracturing governs cataclasis during early fault slip through particle-particle fragmentation, chipping governs the late stages during which grain edges are removed after greater amounts of fault displacement (Billi, 2010; Ferraro et al., 2018). Cataclasis can produce different grain-size distributions with fractal dimensions $(D)$ that provide information on the characteristics of fracturing (e.g., Blenkinsop, 1991; Sammis et al., 1986, 1987). For example, a fractal dimension of $D=2.580$ can result from the self-similar fracturing of a three-dimensional object, such as a cube. In addition to obtaining $D$ via linear fitting in Figure 7, one can also determine $D$ via

$$
D=\frac{3 \log (f)}{\log (F)}+3
$$

where $F$ is the number of fragments created and $f$ is the fragmentation fraction, defined as $f=C / F$, with $C$ being the number of fragments that are fragmented further. Fragmentation of a cube produces eight cubes $(F=8)$ of $1 / 2$ the width of the original cube (Heilbronner \& Barrett, 2014). With $F=8$, it follows that for $f=8 / 8,100 \%$ of the newly formed grains are fragmented again, which results in a fractal dimension of $D=3.000$. Our fractal dimensions of $D=2.887$ and $D=2.833$ (Figure 7) can be achieved with a fragmentation fraction of $f=7 / 8$, giving $D=2.807$. Such high $D$-values are reported for natural faults with intense grain-size reduction (Billi \& Storti, 2004) and are predicted by numerical simulations (Abe \& Mair, 2005). The agreement between the theoretical and our measured values suggests that the cataclasite experienced a high degree of fragmentation due to particle-particle interaction. Furthermore, a value of $D=1.574$ from ACOM-TEM (Figure 7) may correspond to a low degree of fragmentation with $f=3 / 8$ yielding $D=1.585$ (see Equation 1). We propose that the difference in $D$ between the bulk cataclasite and the nanogranular volume arises from a difference in the degree of fragmentation. A lower $D$ of 1.574 may, therefore, indicate a different control on particle size involving a minor degree of particle-particle fragmentation. We suggest that the change in fractal dimension within the same fault rock may reflect a change in fragmentation and thus deformation mechanisms, as also proposed by Keulen et al. (2007).

\subsection{Nanostructures}

The Arkitsa and Schinos faults exhibit different nanostructures in their principal slip zones (PSZs). Whereas the PSZ of the Arkitsa fault is complex directly below the slip surface and includes a layer of nanograins (Figures 4 and 6), the PSZ of the Schinos fault exhibits a similar grain size as its bulk fault rock (Figures 3 and 5). We propose the difference in nanostructural complexity are because the Schinos fault represents 

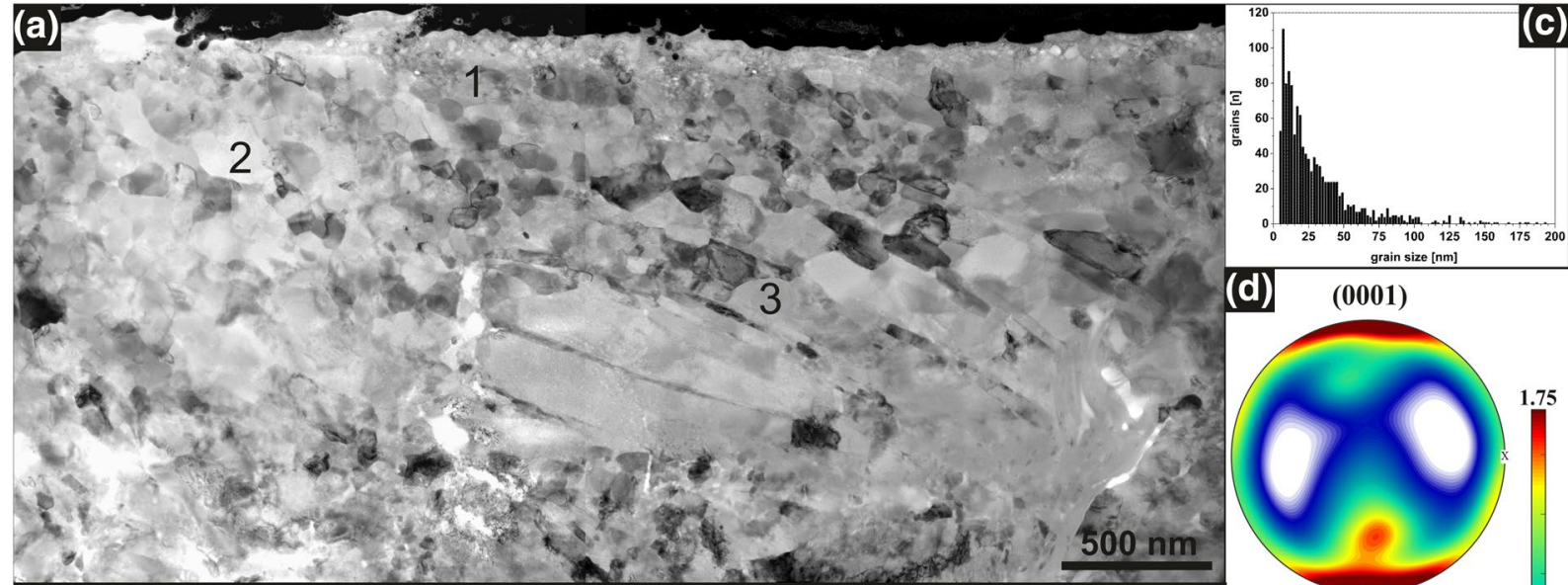

\section{(d) (0001)}
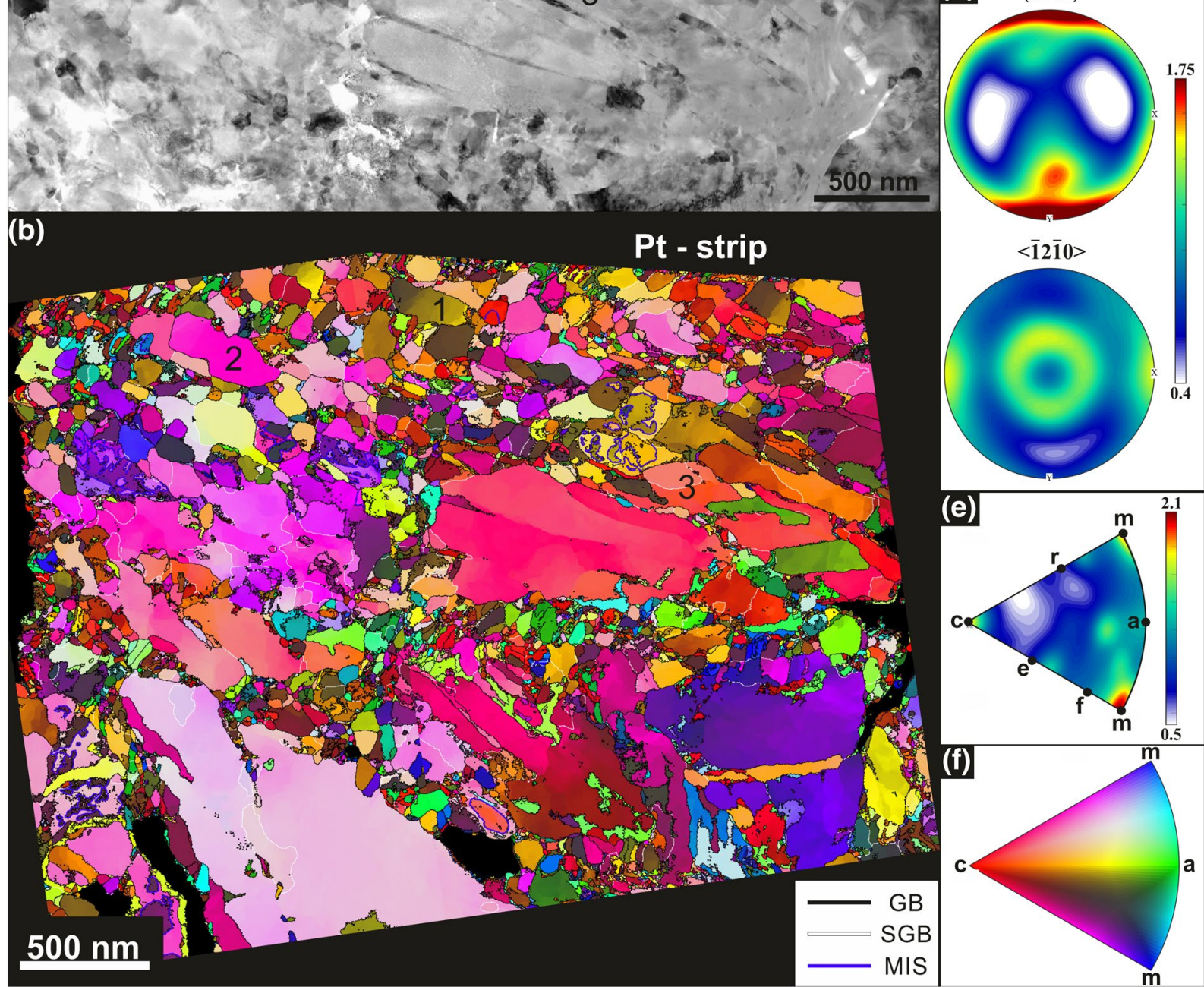

Figure 6. Nanoscale crystal-orientation map. Numbers indicate the same grains for comparison between (a) and (b). (a) BF-STEM image from Figure 4C. (b) Crystal-orientation map color-coded according to the inverse pole figure in (f) indicating the crystal direction aligned with the $Y$-axis of the map. (c) Grain-size distribution of map in (b). (d) Contoured pole figures of (0001) poles and $<1210>$ axes. (e) MIPF of misorientation axes associated with misorientation angles in the range $2-10^{\circ}$. (f) IPF-Y color key for map in (b). GB = grain boundary, SGB = subgrain boundary, MIS = misindexed grain boundary. Due to the electrontransparent nature of the FIB foil and corresponding diffraction behavior, grain-boundary morphologies are less well defined in the ACOM-TEM data compared to the BF-STEM image.

an earlier stage of fault-rock evolution, while the Arkitsa fault accommodated multiple slip events over an extended deformation history.

Slip along the PSS would result in the introduction of plastic strain accompanied by a thermal spike through shear heating (Rice, 2006) during a seismic event. The Schinos nanostructure, with a high, free dislocation density and triple junctions (Figures $5 \mathrm{a}$ and $5 \mathrm{~b}$ ), resembles that of metals subjected to a process known as cold-rolling and annealing (Humphreys \& Hatherly, 2004). The procedure involves the introduction of high-plastic strain followed by static high-temperature treatment to induce microstructural changes. The typical range for industrial cold-rolling is about $60-180{ }^{\circ} \mathrm{C}$ (Hollandt et al., 2010), corresponding to 


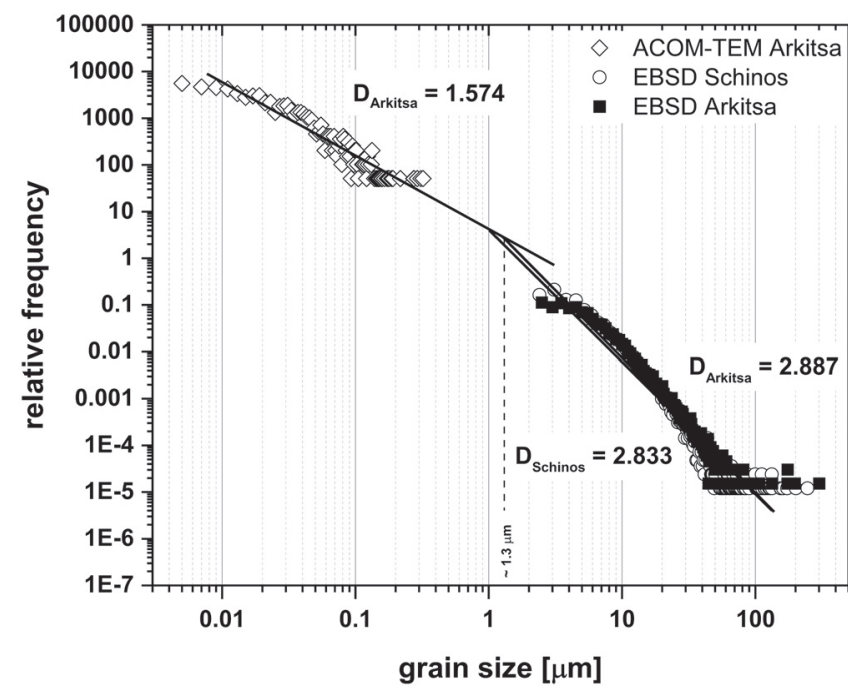

Figure 7. Fractal-dimension plot of grain-size data from both fault exposures. The fractal dimensions of the Arkitsa data sets are $D=2.887$ (EBSD) and $D=1.574$ (ACOM-TEM). The fractal dimension of the Schinos data set is $D=2.833$ (EBSD).
0.05-0.11 times the melting temperature, $T_{\mathrm{m}}$, for steel. It is likely that the temperature during the onset of slip of the carbonate faults was at a homologous temperature of about $0.2 T_{\mathrm{m}}\left(300^{\circ} \mathrm{C}\right)$. Cold-rolling and subsequent annealing is a well-established process in engineering leading to grain-boundary migration and recrystallization (Humphreys \& Hatherly, 2004). Dislocation introduction through strain pulses in the low-temperature plasticity regime can result in strain-hardening effects. Addition of thermal energy through heating enables dislocation climb and solid-state diffusion, leading to recovery or recrystallization by static grain growth or grain-boundary migration. The resulting grain size post annealing is smaller compared to the previous microstructure leading to grain-boundary strengthening and hence, toughening of the material. Such deformation processes followed by annealing of the material are already documented in experimentally and naturally deformed olivine (Druiventak et al., 2012; Matysiak \& Trepmann, 2012) and quartz (Trepmann \& Stöckhert, 2013; Trepmann et al., 2017). Repeated straining and subsequent annealing can lead to grain-size reduction and may, therefore, pose a mechanism of nanograin formation.

The $120^{\circ}$ triple junctions of the Arkitsa nanostructure may indicate annealing by grain-boundary migration (Figures 2 and 4). Static recrystallization involves an initial stage during which deformed grains with high, stored strain energy are replaced by recrystallized grains, which may then continue to grow. To evaluate whether significant grain growth can occur during the postseismic and interseismic period, we use the following kinetic model (Covey-Crump, 1997)

$$
d^{1 / n}-d_{0}^{1 / n}=k t=k_{0} t \exp (-H / R T)
$$

where $d$ is the final grain size, $d_{0}$ is the initial grain size, $n$ is a dimensionless constant, $k_{0}$ is a preexponential factor, $t$ is the duration of grain growth, and $H$ is the apparent activation enthalpy. The values of $n$ and $H$ depend on the growth-controlling process. In the case of a grain-boundary controlled system, with no second phases (pure system) $n=0.5$. For an impure system where coalescence of a second phase occurs by volume diffusion (wet case) $n=0.33$ and for an impure system where coalescence of a second phase occurs by grain-boundary diffusion, $n=0.25$ (Covey-Crump, 1997). Assuming fluid-present conditions based on observations that suggest the presence of portlandite $\left(\mathrm{Ca}(\mathrm{OH})_{2}\right)$ during deformation (Ohl et al., 2020), we set $n=0.33$. This interpretation results in the following parameters: $k_{0}=2.514 \times 10^{9} \mu \mathrm{m}^{1 / n} \mathrm{~s}^{-1}, 1 / n \approx 3$ and $H=173.6 \mathrm{~kJ} \mathrm{~mol}^{-1}$ (Covey-Crump, 1997). To assess the potential for fluid-assisted postseismic grain growth due to the ambient temperature at depth, we consider the borehole temperatures from the outcrop areas (Lambrakis et al., 2014; Metaxas et al., 2010; Papoulis et al., 2013). We assume a geothermal gradient of $65-75^{\circ} \mathrm{C} / \mathrm{km}$ and a typical seismogenic crustal depth of 3-5 km (Scholz, 1988) resulting in an ambient temperature of about $300{ }^{\circ} \mathrm{C}$. Annealing of the nanostructure for 1 year, at a temperature of $300{ }^{\circ} \mathrm{C}$, with $d_{0}=0.1 \mu \mathrm{m}$, leads to a final grain size of $d=2.3 \mu \mathrm{m}$. Therefore, not only under short-lived, coseismic temperature spikes but also during the interseismic period, grain growth may contribute to the formation and modification of the microstructure. However, the grain-size distribution in Figure $6 \mathrm{~b}$ contains grains $<50 \mathrm{~nm}$ in size, illustrating that our grain-growth approximation provides an upper limit. Nonetheless, our assessment of interseismic grain growth supports our suggestion that a cohesive nanogranular fault rock may be generated by high-plastic strain deformation and short annealing times.

\subsection{Deformation Mechanisms}

\subsubsection{Grain-Boundary Sliding}

GBS has been proposed as a deformation mechanism for fine-grained fault rocks during seismic slip (De Paola et al., 2015). Langdon (2006) describes two possible types of GBS: Rachinger sliding and Lifshitz sliding. Rachinger sliding is defined by the relative displacement of adjacent grains, with strain compatibility 
maintained by dislocation motion in grain interiors. Therefore, Rachinger sliding is commonly referred to as dislocation-accommodated grain-boundary sliding in the geological literature (Hansen et al., 2011; Hirth \& Kohlstedt, 1995). In contrast, Lifshitz sliding is coupled to vacancy diffusion along stress gradients during Nabarro-Herring or Coble diffusion creep. GBS is an essential process that contributes to superplasticity, which is the ability of a material to deform to strains on the order of $1,000 \%$ without failure (Komura et al., 2001; Langdon, 2006). The term superplasticity does not indicate a deformation mechanism but is a phenomenological description. In experiments on metals (Langdon, 2006) and calcite (Rutter et al., 1994; Schmid et al., 1977) superplastic behavior is most pronounced in a regime in which strain rate is proportional to approximately the square of both stress and grain size. This mechanical behavior is associated with Rachinger sliding in materials with grains that are generally too small to host subgrain boundaries (Langdon, 2006). An important consideration for seismogenic faults is that experiments by Komura et al. (2001) on metals demonstrate a strong strain-rate dependence for superplasticity, where strain rates $>1 \mathrm{~s}^{-1}$ reduce the achievable strain from $1,000 \%$ down to $100 \%$. This observation presents a challenge to the interpretation of superplastic behavior from microstructure, or nanostructure in the high-strain rate context of coseismically produced materials.

In many metals, GBS is proposed as a deformation mechanism of nanogranular materials. The in-situ TEM deformation study by Kumar et al. (2003) on nanograined Ni with grain sizes $<30 \mathrm{~nm}$ revealed that GBS can be an important deformation mechanism even at room temperature. Those authors report the involvement of dislocations during the deformation process and emphasize the dominant role of dislocation-mediated plasticity. Experimental evidence suggests that at grain sizes of $<20 \mathrm{~nm}$ the material strength decreases and produces an inverse Hall-Petch effect (Kumar et al., 2003). Another study by Lu et al. (2000) also indicates that GBS may be significant in nanomaterials at lower homologous temperatures. At grain sizes below $10 \mathrm{~nm}$, dislocation activity ceases and GBS dominates. Whether in-situ nanoscale deformation behavior within a TEM can be generalized to be representative of bulk deformation behavior remains a matter of debate (Ma, 2004). Nevertheless, deformation of materials with grain sizes $\gtrsim 30 \mathrm{~nm}$ that involves GBS can also involve dislocation activity. The combination of dislocations we observe (Figures 4 and 5), subgrain boundaries in EBSD (Figures 2 and 3), and the nanoscale CPO consistent with the activity of known slip systems (Figure 6) suggests that dislocation activity plays an important role during the formation and deformation of the nanostructure.

A mechanism that combines GBS and dislocation activity is disGBS and has been proposed as a deformation mechanism for several minerals, including calcite (Walker et al., 1990), olivine (Hansen et al., 2011; Hirth \& Kohlstedt, 1995), and quartz (Tokle et al., 2019). Based on the microstructures and mechanical data from their experiments on olivine, Hansen et al. (2011) propose a similar disGBS mechanism to the model by Langdon (2006), in which the subgrain size is smaller than the grain size. Dislocation activity during disGBS may be an explanation for the CPO observed by Hansen et al. (2011) and may be an alternative interpretation to crystal plasticity for the microstructure and nanostructure observed here. Schmid et al. (1977) and Walker et al. (1990) observed displacements across grain boundaries on the precut surfaces of split cylinders deformed in regimes with nonlinear stress dependencies. Rutter et al. (1994) use the similarities of stress and grain-size exponents which fit with the later proposed model by Langdon (2006). Likewise, several studies (e.g., Rutter et al., 1994; Schmid et al., 1977; Walker et al., 1990) have measured regimes in which the stress and grain-size exponents of calcite are broadly in agreement with the models of disGBS reviewed by Langdon (2006). Rutter et al. (1994) report a CPO apparently formed during high-temperature creep deformation, where one of the experiments reached a strain of 600-1,000\%, representing superplastic flow. Those authors interpreted their results to indicate a contribution from intracrystalline plastic flow involving cyclic dynamic recrystallization but did not exclude the contribution of GBS.

High-strain torsion experiments $(\gamma=20)$ by Barnhoorn et al. (2005), however, demonstrate that postdeformational annealing can change the microstructural appearance and produce a foam structure where the grain morphologies are indistinguishable from a GBS microstructure. The CPO formed during initial deformation is enhanced with progressive annealing as the axis distributions become tighter. In addition, the calcite deformed by Barnhoorn et al. (2005) has microstructural characteristics indicating incomplete reworking of the starting material used and shares similarities with our microstructure (Figure 2). Specifically, the slightly lobate grain boundaries and not ideal triple junctions of the foam microstructure are comparable. 
These similarities and a pronounced CPO across different scales suggest that the microstructures of the studied carbonate faults may be influenced by other deformation processes e.g., crystal plasticity, than exclusively GBS.

\subsubsection{Crystal Plasticity}

The occurrence of CPOs suggests the activation of one or more slip systems in both Greek faults. Multiscale analysis of crystal orientations (Figures 2, 3, and 6) reveals that the CPO present at the nanoscale in the PSZ is also present in the adjacent cataclasite. The distributions of (0001) planes and $<\overline{1} 2 \overline{1} 0>$ axes from the Arkitsa fault are consistent with CPOs present in previous carbonates experimentally deformed under both seismic and subseismic conditions (Demurtas et al., 2019; Kim et al., 2018; Pozzi et al., 2019; Smith et al., 2013; Verberne et al., 2013). However, the experimental studies have not yet provided detailed slip-system analyses. The combined evidence of calcite (0001) planes aligned parallel to the slip plane, $<\overline{1} 2 \overline{1} 0>$ axes aligned parallel to the slip direction and the distribution of subgrain-misorientation rotation axes indicates the activation of the $(0001)<\overline{1} 2 \overline{1} 0>$ glide system (Figures $2 \mathrm{~d}$ and $2 \mathrm{e}$ ). Subgrain-boundary misorientation axes (Figure 2e) parallel [0001] are consistent with the presence of twist boundaries parallel to the (0001) plane and consisting of $<\overline{1} 2 \overline{1} 0>$ screw dislocations while misorientation axes around $<10 \overline{1} 0>$ are consistent with the presence of tilt boundaries consisting of $(0001)<\overline{1} 2 \overline{1} 0>$ edge dislocations. Both types of boundaries can be produced by activation of the $(0001)<\overline{1} 2 \overline{1} 0>$ glide system. We note that the ring pattern in the center of the $\langle\overline{1} 2 \overline{1} 0>$ pole figure (Figure $6 \mathrm{c}$ ) is likely an artifact arising from diffraction pattern indexing during ACOM-TEM analysis. De Bresser and Spiers (1997) performed a detailed experimental study on calcite single crystals, in which they identified slip systems based on analysis of the traces of slip bands. In their experiments, the $(0001)<\overline{1} 2 \overline{1} 0>$ slip system was activated in the temperature range of $600-800{ }^{\circ} \mathrm{C}$.

In contrast to the Arkitsa fault, misorientation axes of subgrain boundaries in the Schinos fault are dominantly parallel to $<\overline{1} 2 \overline{1} 0>$, with only secondary maxima parallel to $<10 \overline{1} 0>$ and [0001] (Figure 3). Misorientation axes parallel to $<\overline{1} 2 \overline{1} 0>$ indicate the presence of subgrain boundaries consisting of edge dislocations on the $f\{\overline{1} 012\}<10 \overline{1} 1>$ or $r\{10 \overline{1} 4\}<\overline{2} 021>$ slip systems. In the experiments of De Bresser and Spiers (1997) the $f\{\overline{1} 012\}<10 \overline{1} 1>$ slip system was activated at temperatures between 600 and $800{ }^{\circ} \mathrm{C}$, while $\{r\}$ slip was activated over a broader temperature range of $300-800{ }^{\circ} \mathrm{C}$. These two slip systems also exhibit different critical resolved shear stress (CRSS). At temperatures $>600^{\circ} \mathrm{C}$, the CRSS for $f<10 \overline{1} 1>$ is less $<20 \mathrm{MPa}$ and for $r<\overline{2} 021>$ is $\leq 10 \mathrm{MPa}$. Overall, we suggest that the misorientation axes around $<\overline{1} 2 \overline{1} 0>$ (Figures $3 \mathrm{a}$ and 3e) most likely originate from edge dislocations on the $r<\overline{2} 021>$ slip system as the CPO indicates that this system is more favorably aligned for slip than is the $f<10 \overline{1} 1>$ system. The change from rotation around $<\mathrm{a}>$ to additional rotation around [0001] and $<\mathrm{m}>$ indicates the activation of more than one slip system, in particular the additional activation of $(0001)<\overline{1} 2 \overline{1} 0>$. The high temperatures indicated by the misorientation analyses are in agreement with our previous estimates for these faults of $600-800{ }^{\circ} \mathrm{C}$, but $<1000{ }^{\circ} \mathrm{C}$, based on the degree of $\mathrm{sp}^{2}$ hybridization of partly hybridized amorphous carbon (Ohl et al., 2020). Whether or not the potential high-temperature signals are diagnostic for deformation at coseismic velocities warrants further investigation. Because a systematic experimental study of slip systems in subseismic and seismically deformed carbonate fault rocks is lacking, more experiments are required to investigate potential differences in CPOs, including between dry and wet environmental conditions.

To evaluate whether changes in slip systems indicate shear-heating-induced temperature gradients, we analyzed EBSD subsets over a range of distances from the PSS to test for systematic variation in the temperatures associated with the recorded slip systems (De Bresser \& Spiers, 1997). We find that overall, the Arkitsa (Figure 2a) and Schinos (Figure 3a) fault rocks do not exhibit systematic changes in misorientation axes and hence, slip systems or associated temperatures with distance from the PSZ. If the faults experienced seismic slip, a temperature gradient was not recorded. However, the Schinos fault does display a nonsystematic variation in the intensities of misorientation-axes maxima parallel to $<\overline{1} 2 \overline{1} 0>$ and [0001], suggesting variation in the contributions of $r$-slip and (c)<a $>$. The underlying cause for these nonsystematic changes in misorientation axes remains unknown and warrants further investigation. Nevertheless, if we can reliably apply the slip system temperature correlations from De Bresser and Spiers (1997), the common feature of both faults is the high temperatures suggested by the activation of specific slip systems. However, we note 
that the experiments carried out by De Bresser and Spiers (1997) were performed at $3 \times 10^{-5} \mathrm{~s}^{-1}$ and extrapolation of the results to higher strain rates should be undertaken with caution.

Combined numerical models and deformation experiments by Demurtas et al. (2019) indicate that a temperature increase of approximately $\Delta T=620{ }^{\circ} \mathrm{C}$ decays to about $50{ }^{\circ} \mathrm{C}$ over a thermal diffusion distance of $2 \mathrm{~mm}$ inside carbonate fault gouge with $1 \mathrm{~s}$. Assuming a single shear-heating event, the resulting temperature diffusion front could be captured as a change in activated slip systems and associated CPOs. However, the absence of differences in slip systems with decreasing temperature away from the PSS may suggest a later thermal overprint of the cataclasite by more than one event. Based on the microstructures in Figure 4a, this overprint may lead to annealing of the microstructure and a loss of an apparent temperature diffusion profile. Consequently, the analyzed cataclasite could contain several slip surfaces which are no longer discernible. The agreement between CPO and subgrain misorientations suggests that crystal plasticity was the main deformation process to produce the CPO rather than other, more exotic CPO-formation mechanisms such as surface energy interactions (Toy et al., 2015) or coupled solution and growth (Power \& Tullis, 1989). Overall, our results show that crystal plasticity played a role within the whole fault-rock volume.

Water can have an influence on crystal-plastic deformation. It is known for quartz that a higher water content can result in a transition of active slip systems from slip in the <a> directions to slip in the [c] direction (Blacic, 1975) and a similar trend is observed by Tokle et al. (2019) where added water can result in a different stress exponent. The temperature threshold for the transition between different dislocation creep regimes in quartz can also be lowered by about $100{ }^{\circ} \mathrm{C}$ by the addition of water (Hirth \& Tullis, 1992). However, Stipp et al. (2002) point out that the regimes identified by Hirth and Tullis (1992) may correspond to different types of dynamic recrystallization. The effect of water content on fabric transition is also known from experiments on olivine where, e.g., typed-B ((010)[001]) and type-C ((100)[001]) CPOs are more common with higher water content, whereas type-A ((010)[100]) is most common without water (Jung \& Karato, 2001). Deformation experiments on wet calcite at seismic velocities show a more significant drop in friction coefficient compared to dry experiments (e.g., Violay et al., 2014; Chen et al., 2017) and the development of a similar CPO to the one reported here (Demurtas et al., 2019). It has been inferred that the presence of water can promote hydrolytic weakening and influence dislocation glide and climb in calcite (Liu et al., 2002). We speculate that the above-mentioned examples of water influencing crystal-plastic deformation may also have an influence on the activity of specific glide systems and its activation temperature in crustal carbonate faults. The addition of water could explain why De Bresser and Spiers (1997) consider the (c)<a> slip system to be of minor importance in their experiments, which are performed dry and at low-strain rates. The potential influence of water on crystal-plastic deformation suggests that the proposed temperature range for the activation of $(\mathrm{c})<\mathrm{a}>\left(600-800{ }^{\circ} \mathrm{C}\right)$ and $r$-slip $\left(300-800{ }^{\circ} \mathrm{C}\right)$ may be different or lower in other situations and may explain the absence of a temperature gradient in Figures 2 and 3: essentially no temperature gradient was produced. In such a case, the syn-deformational temperature would evolve along the water-vapor transition as suggested by Chen et al. (2017).

The development of CPOs has been reported in natural carbonate faults before. For example, Smith et al. (2013) and Kim et al. (2018) report a similar CPO and Kim et al. (2018) speculate about the contribution of crystal plasticity during deformation. Our subgrain misorientation analysis matches the inverse pole figures presented by displaying a rotational maximum around [0001] close to the slip surface (Kim et al., 2018). The authors report that the intensity of the maximum weakens over $10 \mathrm{~cm}$ away from the slip surface. This may indicate that temperature is not the main governing factor for the activation of the (c) $<a>$ glide system because temperature diffusion would reach background values after about $2 \mathrm{~mm}$ (Demurtas et al., 2019). In contrast to the fault rocks of Kim et al., (2018), our analyses do not show a pronounced region of plastic deformation. In addition, high dislocation densities are reported from numerous studies of natural faults, e.g., Collettini et al. (2014) who also shows free dislocations, as well as nanometric, dislocation-free subgrains comparable to our observations in Figure 5.

\subsection{Deformation Mechanism Maps}

In the following, we compare our microstructural observations and interpretations of deformation mechanisms with theoretical considerations. We constructed deformation-mechanism maps (DMMs) (Figure 8) (Ashby, 1972) for both the approximate ambient temperature conditions of $300{ }^{\circ} \mathrm{C}$ during the interseismic 

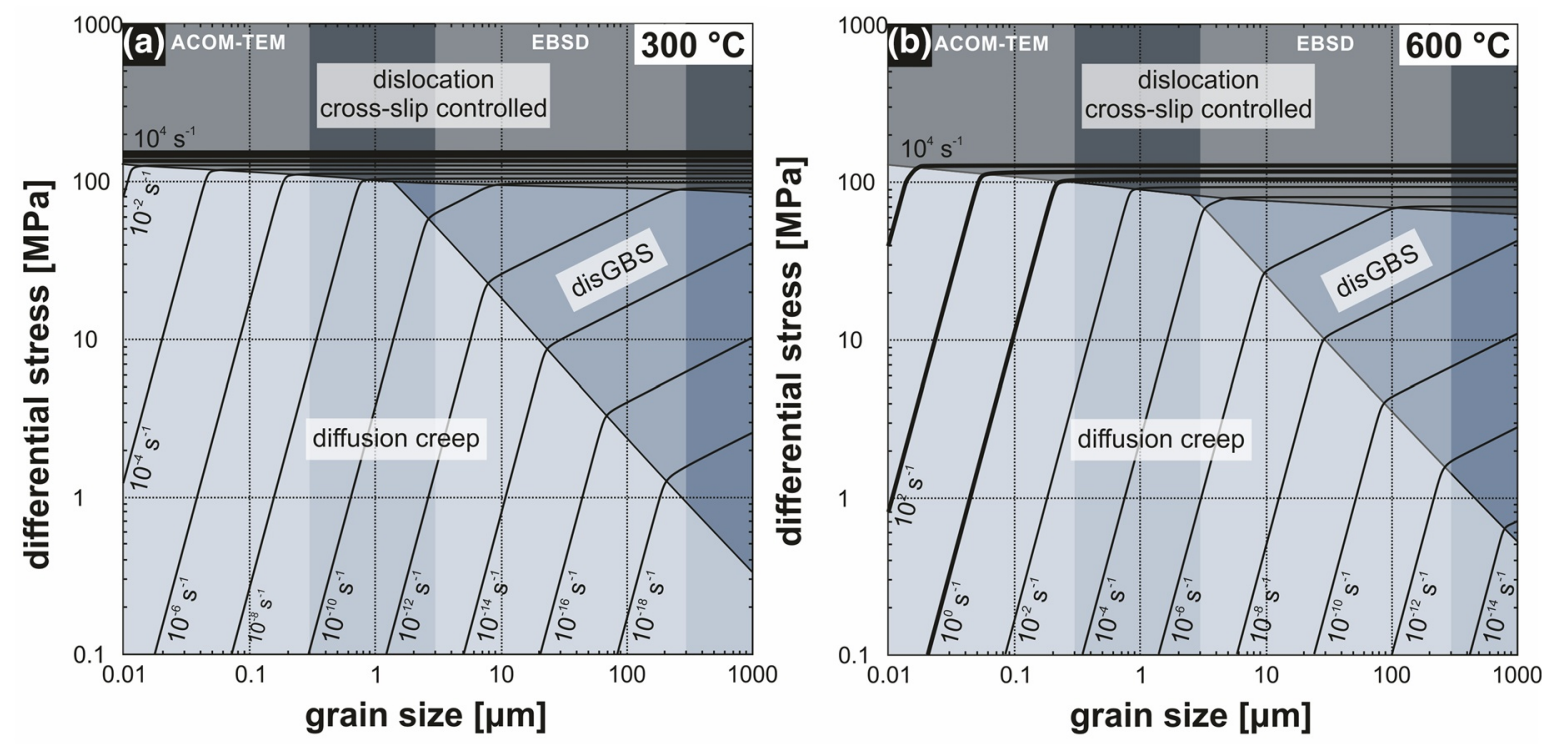

Figure 8. Deformation-mechanism maps for calcite at (a) $300{ }^{\circ} \mathrm{C}$ and (b) $600{ }^{\circ} \mathrm{C}$. Light-shaded areas indicate the grain-size ranges from crystal-orientation mapping by ACOM-TEM and EBSD. Deformation mechanism maps with three domains: diffusion creep (Herwegh et al., 2003), disGBS (Walker et al., 1990), and cross-slip controlled dislocation glide (De Bresser, 2002). Bold lines represent relevant strain rates.

period and onset of slip at a depth of 3-5 km and, the potential high-temperature conditions of $600{ }^{\circ} \mathrm{C}$ attained by seismic shear heating, constrained by the observed $\mathrm{CPO}$ and $\mathrm{sp}^{2}$ hybridization of partly hybridized amorphous carbon (Ohl et al., 2020). The general parameters utilized are $A$ as a material-dependent factor, $n$ as the stress exponent, $p$ as the grain-size exponent, $B$ as a temperature-dependent constant, and $Q$ as the activation energy. For the flow laws in Figure 8, we utilized the values $A=10^{7.63}, n=1.1, p=3.3$, $Q=200 \mathrm{~kJ} \mathrm{~mol}^{-1}$ for diffusion creep (Herwegh et al., 2003); $A=10^{4.93}, n=1.67, p=1.87, Q=190 \mathrm{~kJ} \mathrm{~mol}^{-1}$ for disGBS (Walker et al., 1990) and for cross-slip-controlled plasticity we used a power law approximation with $A=10^{16.65}, B=2.431$, and $Q=584 \mathrm{~kJ} \mathrm{~mol}^{-1}$ according to Verberne et al. (2015), based on the initial work by De Bresser (2002). As a first approximation, we only consider flow laws for materials with a grain-size range of $10^{-8}-10^{-3} \mathrm{~m}$, comparable to the grain sizes of our faults. We also investigated a flow law derived for water-assisted grain-boundary diffusion described by Verberne et al. (2019) and found that it produced the same slope of strain rate contours but predicted lower strain rates than the flow law by Herwegh et al. (2003). Hence, we include the flow law by Herwegh et al. (2003) because it is more reasonable for a high-strain rate environment. Future investigations will also need to determine the impact of flaw laws explicitly derived for nanogranular materials (Mohamed, 2011).

Figure 8 displays DMMs calculated for temperatures of $300{ }^{\circ} \mathrm{C}$ and $600{ }^{\circ} \mathrm{C}$ representing the onset of seismic slip and potential peak deformation conditions, respectively. The difference in temperature has little influence on the position of the field boundaries but has a significant impact on the predicted strain rates. The constraints on the grain sizes in this study are good, but we lack reliable estimates of the stresses. At lower stresses, $\lesssim 100 \mathrm{MPa}$, more typical of shallow faults (e.g., Behr \& Platt, 2014) the material is predicted to deform by diffusion creep and/or disGBS, depending on grain size. Close to a field boundary, dislocation activity may contribute to the total strain even within the diffusion creep field. Figure 8a suggests that at strain rates of $>1 \mathrm{~s}^{-1}$ and a temperature of $300{ }^{\circ} \mathrm{C}$, approximating the onset of seismic slip, calcite would deform by cross-slip controlled dislocation glide. Figure $8 \mathrm{~b}$ indicates that at $600{ }^{\circ} \mathrm{C}$ diffusion creep following the flow law of Herwegh et al. (2003) can accommodate a strain rate of $>1 \mathrm{~s}^{-1}$, in materials with grain sizes of $<100 \mathrm{~nm}$ at stresses $<10 \mathrm{MPa}$. At $600^{\circ} \mathrm{C}$, coseismic strain rates $\left(1-10^{4} \mathrm{~s}^{-1}\right)$ can be accommodated in the PSS by either diffusion creep or plasticity depending on the differential stress. In general, the DMMs predict that seismic strain rates could be accommodated by cross-slip-controlled dislocation glide at stresses > $100 \mathrm{MPa}$.

We have shown that crystal plasticity played a role during the deformation of fault rocks within the vicinity of principal slip surfaces. Although the DMMs in Figure 8 predict the operation of deformation mechanisms 
known to not produce a strong CPO, our microstructural and nanostructural observations indicate the activation of several slip systems resulting in CPO development. Future studies need to further evaluate the competition between crystal plasticity and GBS processes during the seismic cycle. Advances may be made by combining microstructural observations and DMMs as we have, and by considering dynamic coseismic changes of different deformation mechanisms.

\subsection{Rheological Considerations}

\subsubsection{Piezometric Equilibrium and Dynamic Recrystallization}

The analysis above indicates that crystal plasticity and recrystallization are feasible even under upper-crustal conditions in the brittle regime. Nevertheless, crystal plasticity and GBS processes will be cooperating mechanisms during fault rock deformation. To further decipher the physical nature behind coseismic deformation processes, Pozzi et al. (2019) proposed the establishment of a piezometric equilibrium during dynamic recrystallization between GSI and GSS deformation mechanisms. The authors propose that this equilibrium promotes rheological weakening during seismic slip due to cycles of grain-size reduction and thermally driven grain growth. We can further assess the piezometric relationship for recrystallized calcite grains with the relation proposed by Platt and De Bresser (2017)

$$
D=K \sigma^{-p}
$$

where $D$ is the recrystallized grain size in $\mu \mathrm{m}, K=1,243, \sigma$ is the differential stress in MPa, and $p=1.09$. For the cataclasite region with grain sizes of $\sim 5-2 \mu \mathrm{m}$, Equation 3 predicts differential stresses in the range 158-365 MPa. This range of differential stress would plot inside the field of dislocation cross-slip controlled deformation in Figure 8, regardless of grain size, and suggests that crystal plasticity was the major contributor to accommodate strain. For the foam nanostructure (Figure 6) with grain sizes of $\sim 200-20 \mathrm{~nm}$, Equation 3 predicts differential stresses in the range 3-24 GPa. While the differential stresses for the cataclasite are plausible on a fault plane, the potential differential stresses estimated for the foam nanostructure are implausibly high and demonstrate that the piezometric relationship of Platt and De Bresser (2017), which was calibrated for much coarser grain sizes, is not applicable in this context. Either the piezometric relationship has a different slope at these finer grain sizes or the nanograins formed by mechanisms other than dynamic recrystallization. In such a case, static recrystallization may be able to reach such small grain sizes as a formation mechanism for nanograins and would not reflect differential stresses during deformation.

\subsubsection{Postseismic Annealing and Fault Rock Strength}

Our observations of the grain-boundary morphology within the Arkitsa nanostructure (Figure 4c) suggest that postseismic annealing occurred via static recrystallization and grain growth through grain-boundary migration. We define two foam nanostructures, old and new, depending on the overprinting relationship. The older foam nanostructure lies at a greater distance from the PSS (Figure 4c, white circle), while the new foam nanostructure borders the PSS (Figure 4c, black circles). We interpret apparent traces of discontinuities that displace grains (Figure 4c) as fracture planes originating from the PSS. These fractures cross-cut grains of the interlocked nanostructure overprinting the old foam structure (Figure 4c). Larger grains within the old foam nanostructure (Figure 4c, white circle) are truncated by fractures that cannot be traced back to the PSS but terminate within the new foam nanostructure (Figure 4c, black circle), instead. The resulting cross-cutting relationships suggest fault reactivation after static recrystallization. Angular relations indicate that the fractures are Riedel shears (Verberne et al., 2013) and suggest that slip along the PSS may have also taken place during an advanced stage of nanostructural evolution.

To assess the influence of grain size on the strength of the PSZ, we calculate the required minimum shear stress, $\sigma_{\mathrm{s}}$, to fracture a grain of size $d[\mathrm{~m}]$ using a modified Hall-Petch equation (Sammis \& Ben-Zion, 2008)

$$
\sigma_{\mathrm{s}}=Y / 2=\frac{2 C K_{\mathrm{Ic}}}{\sqrt{d}},
$$


where $C=\sqrt{\frac{2}{3}}$ and $K_{I c}=0.39 \mathrm{MPa} \sqrt{m}$ (calcite, Broz et al., 2006). For grain sizes of $\sim 5-2 \mu \mathrm{m}$, Equation 4 predicts minimum shear stresses in the range 285-450 MPa. For the median grain size of $21 \mathrm{~nm}$ from ACOM-TEM, Equation 4 predicts a minimum shear stress of $4.4 \mathrm{GPa}$. Given the spread of the grain-size distribution, we also determine $\sigma_{\mathrm{s}}$ for a grain size of $200 \mathrm{~nm}$ (Figures 6a and 6b) and obtain 1.4 GPa. Based on these calculations, it is evident that with decreasing grain size, slip localization onto the PSS increases because the required shear stress to fracture grains increases. A potential explanation is the decreasing distance between dislocation pinning points leading to a grain-size dependent increase in yield stress with decreasing grain diameter (Kato et al., 2008). The modified Hall-Petch equation, which we note is derived from fitting empirical data from $\mathrm{Al}_{2} \mathrm{O}_{3}$ spheres and uses an empirically derived value for $K_{I c}$ from microindentation, should be applied with caution. Alternatively, either local grain-scale stresses may be higher than the overall average stress state of the fault during slip or fractures develop preferentially along zones of weakness, such as cleavage and twin planes.

The localization of slip can be observed over 6 orders of magnitude ( $\mu \mathrm{m}-\mathrm{m})$ and suggests a repeated toughening of the microstructure by grain-boundary strengthening. Our microstructural observations coupled to DMM predictions suggest that at small grain sizes diffusion creep and dislocation creep were active. Deformation by GBS would result in stretching and elongation of the host-rock clasts (Figures 2a and 3a) but the initial shape of the cataclasite fragments is preserved despite showing an internal, polygonal structure expected to promote GBS. This example is further illustrated by another clast in a transition stage consisting half of a fine-grained microstructure and half of a single crystal (Figure 2a, white lasso). These examples show that the internal structure is not diagnostic for GBS. Grain-size reduction by deformation and annealing suggests that with evolving localization, the fault plane becomes progressively stronger with every annealing step. This proposition supports the existence of a grain-boundary strengthening effect within the fault rock volume. Figure 1d shows the presence of a secondary slip surface which develops inside the Schinos cataclasite and we propose that its formation was the first microscale evidence for the locking of the fault rock volume immediately below the PSS. This interpretation is consistent with photographs of the fault exposures (Figures $1 \mathrm{~b}$ and $1 \mathrm{~d}$ ) that show various late-stage fault planes which cross-cut inside the wider fault damage zone. Multiple slip surfaces like those typical in any fault zone may be the macroscopic expression of a repeated grain-boundary strengthening effect. Ultimately, the grain size along the fault plane may reach a critical limit, prompting the fault plane to jump and localize elsewhere inside the damage zone leading to the formation of multiple slip surfaces.

\section{Conclusion}

The subgrain misorientations and the matching crystallographic preferred orientations across different scales indicate that crystal plasticity played a role during fault rock formation in the Arkitsa and Schinos fault. Although the precise nature of slip systems at subseismic velocities are unknown, our results suggest that the slip systems inferred from subgrain misorientation analysis potentially indicate high temperatures during coseismic deformation or the influence of water. Nevertheless, future studies need to further evaluate the applicability of slip-system analyses as paleoseismicity indicators, especially comparing dry and wet deformation. Plastic straining and tempering, described as cold working and annealing, offers an alternative mechanism to produce a cohesive nanogranular material. Paleopiezometric estimations based on grain sizes immediately below the slip surface suggest that either dynamic recrystallization did not take place or at least did not follow the piezometer calibrated by low-strain rate experiments. The cyclic repetition of plastic strain, annealing, and static recrystallization via grain-boundary migration produces a grain-boundary strengthening effect until the grain size reaches a critical minimum. This strengthening effect forces the fault plane to relocate inside the fault damage zone, resetting the deformation cycle.

\section{Data Availability Statement}

All data sets found in this manuscript will be made available open access through the European Plate Observing System at https://public.yoda.uu.nl/geo/UU01/A77O7X.html. 


\section{Acknowledgments}

This study was funded by the Dutch research organization (NWO) with the project number ALWOP.2015.082. O. Plümper was supported by an ERC starting grant "nanoEARTH" (852069). The authors also thank Edgar Rauch for discussion and input regarding ACOMTEM, A. Niemeijer, E. Korkolis, and J. H. P. De Bresser for discussions, and I. Koukouvelas for the outcrop locations. The TEM facility in Lille (France) was supported by the Conseil Regional du Nord-Pas de Calais and the European Regional Development Fund (ERDF).

\section{References}

Abe, S., \& Mair, K. (2005). Grain fracture in 3D numerical simulations of granular shear. Geophysical Research Letters, 32, L05305. https:// doi.org/10.1029/2004GL022123

Ambraseys, N. N., \& Jackson, J. A. (1990). Seismicity and associated strain of central Greece between 1890 and 1988 . Geophysical Journal International, 101(3), 663-708. https://doi.org/10.1111/j.1365-246x.1990.tb05577.x

Ashby, M. F. (1972). A first report on deformation-mechanism maps. Acta Metallurgica, 20(7), 887-897. https://doi. org/10.1016/0001-6160(72)90082-X

Bachmann, F., Hielscher, R., \& Schaeben, H. (2011). Grain detection from 2d and 3d EBSD data-Specification of the MTEX algorithm. Ultramicroscopy, 111(12), 1720-1733. https://doi.org/10.1016/j.ultramic.2011.08.002

Barnhoorn, A., Bystricky, M., Burlini, L., \& Kunze, K. (2005). Post-deformational annealing of calcite rocks. Tectonophysics, 403(1-4), 167-191. https://doi.org/10.1016/j.tecto.2005.04.008

Behr, W. M., \& Platt, J. P. (2014). Brittle faults are weak, yet the ductile middle crust is strong: Implications for lithospheric mechanics. Geophysical Research Letters, 41, 8067-8075. https://doi.org/10.1002/2014GL061349

Billi, A. (2010). Microtectonics of low-P low-T carbonate fault rocks. Journal of Structural Geology, 32, 1392-1402. https://doi.org/10.1016/j. jsg.2009.05.007

Billi, A., \& Storti, F. (2004). Fractal distribution of particle size in carbonate cataclastic rocks from the core of a regional strike-slip fault zone. Tectonophysics, 384, 115-128. https://doi.org/10.1016/j.tecto.2004.03.015

Blacic, J. D. (1975). Plastic-deformation mechanisms in quartz: The effect of water. Tectonophysics, 27(3), 271-294. https://doi. org/10.1016/0040-1951(75)90021-9

Blenkinsop, T. G. (1991). Cataclasis and processes of particle size reduction. Pure and Applied Geophysics, 136(1), 59-86. https://doi. org/10.1007/BF00878888

Broz, M. E., Cook, R. F., \& Whitney, D. L. (2006). Microhardness, toughness, and modulus of Mohs scale minerals. American Mineralogist, 91(1), 135-142. https://doi.org/10.2138/am.2006.1844

Bürgmann, R., \& Dresen, G. (2008). Rheology of the lower crust and upper mantle: Evidence from rock mechanics, geodesy, and field observations. Annual Review of Earth and Planetary Sciences, 36, 531-567. https://doi.org/10.1146/annurev.earth.36.031207.124326

Chen, J., Niemeijer, A., Yao, L., \& Ma, S. (2017). Water vaporization promotes coseismic fluid pressurization and buffers temperature rise. Geophysical Research Letters, 44, 2177-2185. https://doi.org/10.1002/2016GL071932

Collettini, C., Carpenter, B. M., Viti, C., Cruciani, F., Mollo, S., Tesei, T., et al. (2014). Fault structure and slip localization in carbonate-bearing normal faults: An example from the Northern Apennines of Italy. Journal of Structural Geology, 67, 154-166. https:// doi.org/10.1016/j.jsg.2014.07.017

Collier, R. E., Pantosti, D., D'addezio, G., De Martini, P. M., Masana, E., \& Sakellariou, D. (1998). Paleoseismicity of the 1981 Corinth earthquake fault: Seismic contribution to extensional strain in central Greece and implications for seismic hazard. Journal of Geophysical Research, 103(B12), 30001-30019. https://doi.org/10.1029/98JB02643

Covey-Crump, S. J. (1997). The normal grain growth behaviour of nominally pure calcitic aggregates. Contributions to Mineralogy and Petrology, 129(2-3), 239-254. https://doi.org/10.1007/s004100050335

De Bresser, J. H. P. (2002). On the mechanism of dislocation creep of calcite at high temperature: Inferences from experimentally measured pressure sensitivity and strain rate sensitivity of flow stress. Journal of Geophysical Research, 107(B12), 2337. https://doi. org/10.1029/2002JB001812

De Bresser, J. H. P., \& Spiers, C. J. (1997). Strength characteristics of the r, f, and c slip systems in calcite. Tectonophysics, 272(1), 1-23. https://doi.org/10.1016/S0040-1951(96)00273-9

Delle Piane, C., Piazolo, S., Timms, N. E., Luzin, V., Saunders, M., Bourdet, J., et al. (2017). Generation of amorphous carbon and crystallographic texture during low-temperature subseismic slip in calcite fault gouge. Geology, 46, 163-166. https://doi.org/10.1130/G39584.1

De Paola, N., Holdsworth, R. E., Viti, C., Collettini, C., \& Bullock, R. (2015). Can grain size sensitive flow lubricate faults during the initial stages of earthquake propagation? Earth and Planetary Science Letters, 431, 48-58. https://doi.org/10.1016/j.epsl.2015.09.002

Demurtas, M., Smith, S. A., Prior, D. J., Spagnuolo, E., \& Di Toro, G. (2019). Development of crystallographic preferred orientation during cataclasis in low-temperature carbonate fault gouge. Journal of Structural Geology, 126, 37-50. https://doi.org/10.1016/j.jsg.2019.04.015

Di Toro, G., Han, R., Hirose, T., De Paola, N., Nielsen, S., Mizoguchi, K., et al. (2011). Fault lubrication during earthquakes. Nature, 471, 494. https://doi.org/10.1038/nature09838

Di Toro, G., \& Pennacchioni, G. (2004). Superheated friction-induced melts in zoned pseudotachylytes within the Adamello tonalites (Italian Southern Alps). Journal of Structural Geology, 26(10), 1783-1801. https://doi.org/10.1016/j.jsg.2004.03.001

Druiventak, A., Matysiak, A., Renner, J., \& Trepmann, C. A. (2012). Kick-and-cook experiments on peridotite: Simulating coseismic deformation and post-seismic creep. Terra Nova, 24(1), 62-69. https://doi.org/10.1111/j.1365-3121.2011.01038.x

Ferraro, F., Grieco, D. S., Agosta, F., \& Prosser, G. (2018). Space-time evolution of cataclasis in carbonate fault zones. Journal of Structural Geology, 110, 45-64. https://doi.org/10.1016/j.jsg.2018.02.007

Hansen, L. N., Zimmerman, M. E., \& Kohlstedt, D. L. (2011). Grain boundary sliding in San Carlos olivine: Flow law parameters and crystallographic-preferred orientation. Journal of Geophysical Research, 116, B08201. https://doi.org/10.1029/2011JB008220

Heilbronner, R., \& Barrett, S. (2014). Fractal grain size distributions image analysis in Earth sciences (pp. 225-249). Berlin, Heidelberg: Springer.

Herwegh, M., Xiao, X., \& Evans, B. (2003). The effect of dissolved magnesium on diffusion creep in calcite. Earth and Planetary Science Letters, 212(3-4), 457-470. https://doi.org/10.1016/s0012-821x(03)00284-x

Hielscher, R., \& Schaeben, H. (2008). A novel pole figure inversion method: Specification of the MTEX algorithm. Journal of Applied Crystallography, 41(6), 1024-1037. https://doi.org/10.1107/s0021889808030112

Hirth, G., \& Kohlstedt, D. L. (1995). Experimental constraints on the dynamics of the partially molten upper mantle: Deformation in the diffusion creep regime. Journal of Geophysical Research, 100(B2), 1981-2001. https://doi.org/10.1029/94JB02128

Hirth, G., \& Tullis, J. (1992). Dislocation creep regimes in quartz aggregates. Journal of Structural Geology, 14(2), 145-159. https://doi. org/10.1016/0191-8141(92)90053-y

Hollandt, J., Hartmann, J., Struß, O., \& Gärtner, R. (2010). Industrial applications of radiation thermometry. Experimental methods in the physical sciences (Vol. 43, pp. 1-56). Cambridge, MA: Academic Press.

Humphreys, F. J., \& Hatherly, M. (2004). Recrystallization and related annealing phenomena (pp. 215-267). Elsevier Science Ltd.

Jung,H.,\&Karato,S.(2001).Water-inducedfabrictransitionsinolivine.Science,293(5534),1460-1463.https://doi.org/10.1126/science.1062235 
Kaplanis, A., Koukouvelas, I., Xypolias, P., \& Kokkalas, S. (2013). Kinematics and ophiolite obduction in the Gerania and Helicon Mountains, central Greece. Tectonophysics, 595, 215-234. https://doi.org/10.1016/j.tecto.2012.07.014

Kato, M., Fujii, T., \& Onaka, S. (2008). Dislocation bow-out model for yield stress of ultra-fine grained materials. Materials Transactions, 49, 1278-1283. https://doi.org/10.2320/matertrans.MRA2008012

Keulen, N., Heilbronner, R., Stünitz, H., Boullier, A. M., \& Ito, H. (2007). Grain size distributions of fault rocks: A comparison between experimentally and naturally deformed granitoids. Journal of Structural Geology, 29(8), 1282-1300. https://doi.org/10.1016/j. jsg.2007.04.003

Kim, S., Ree, J. H., Han, R., Kim, N., \& Jung, H. (2018). Fabric transition with dislocation creep of a carbonate fault zone in the brittle regime. Tectonophysics, 723, 107-116. https://doi.org/10.1016/j.tecto.2017.12.008

Kokkalas, S., Jones, R. R., McCaffrey, K., \& Clegg, P. (2007). Quantitative fault analysis at Arkitsa, Central Greece, using terrestrial laser-scanning (LiDAR). Bulletin of the Geological Society of Greece, 660, 1959-1972.

Komura, S., Horita, Z., Furukawa, M., Nemoto, M., \& Langdon, T. G. (2001). An evaluation of the flow behavior during high strain rate superplasticity in an Al-Mg-Sc alloy. Metallurgical and Materials Transactions A, 32(3), 707-716. https://doi.org/10.1007/s11661-001-0087-9

Kumar, K. S., Suresh, S., Chisholm, M. F., Horton, J. A., \& Wang, P. (2003). Deformation of electrodeposited nanocrystalline nickel. Acta Materialia, 51(2), 387-405. https://doi.org/10.1016/s1359-6454(02)00421-4

Lambrakis, N., Katsanou, K., \& Siavalas, G. (2014). Chapter 3: Geothermal fields and thermal waters of Greece: An overview. In A. Baba, J. Bundschuh, \& D. Chandrasekharam (Eds.), Geothermal systems and energy resources: Turkey and Greece (Vol. 1, pp. 25-45). Boca Raton, FL: CRC Press.

Langdon, T. G. (2006). Grain boundary sliding revisited: Developments in sliding over four decades. Journal of Materials Science, 41(3), 597-609. https://doi.org/10.1007/s10853-006-6476-0

Larède, V. (2018). Thermal structure of the Aegean lithosphere from numerical modelling (M.Sc. thesis). Utrecht, Netherlands: Department of Earthsciences, Utrecht University.

Limberger, J., Calcagno, P., Manzella, A., Trumpy, E., Boxem, T., Pluymaekers, M., \& van Wees, J. (2014). Assessing the prospective resource base for enhanced geothermal systems in Europe. Geothermal Energy Science, 2, 55-71. https://doi.org/10.5194/gtes-2-55-2014

Liu, J., Walter, J. M., \& Weber, K. (2002). Fluid-enhanced low-temperature plasticity of calcite marble: Microstructures and mechanisms. Geology, 30(9), 787-790. https://doi.org/10.1130/0091-7613(2002)030<0787:FELTPO >2.0.CO;2

Lu, L., Sui, M. L., \& Lu, K. (2000). Superplastic extensibility of nanocrystalline copper at room temperature. Science, 287(5457), 1463-1466. https://doi.org/10.1126/science.287.5457.1463

Ma, E. (2004). Watching the nanograins roll. Science, 305(5684), 623-624. https://doi.org/10.1126/science.1101589

Matysiak, A. K., \& Trepmann, C. A. (2012). Crystal-plastic deformation and recrystallization of peridotite controlled by the seismic cycle. Tectonophysics, 530-531, 111-127. https://doi.org/10.1016/j.tecto.2011.11.029

Mendrinos, D., Choropanitis, I., Polyzou, O., \& Karytsas, C. (2010). Exploring for geothermal resources in Greece. Geothermics, 39(1), 124-137. https://doi.org/10.1016/j.geothermics.2009.11.002

Metaxas, A., Varvarousis, G., Karydakis, G., Dotsika, E., \& Papanikolaou, G. (2010). Geothermic status of Thermopylae-Anthili area in Fthiotida prefecture. Bulletin of the Geological Society of Greece, 43(5), 2265-2273. https://doi.org/10.12681/bgsg.11426

Mohamed, F. A. (2011). Deformation mechanism maps for micro-grained, ultrafine-grained, and nano-grained materials. Materials Science and Engineering: A, 528(3), 1431-1435. https://doi.org/10.1016/j.msea.2010.10.048

Nielsen, S. (2017). From slow to fast faulting: Recent challenges in earthquake fault mechanics. Philosophical Transactions of the Royal Society A Mathematical, Physical and Engineering Sciences, 375(2103), 20160016. https://doi.org/10.1098/rsta.2016.0016

Niemeijer, A., Di Toro, G., Griffith, W. A., Bistacchi, A., Smith, S. A., \& Nielsen, S. (2012). Inferring earthquake physics and chemistry using an integrated field and laboratory approach. Journal of Structural Geology, 39, 2-36. https://doi.org/10.1016/j.jsg.2012.02.018

Ohl, M., Plümper, O., Chatzaras, V., Wallis, D., Vollmer, C., \& Drury, M. (2020). Mechanisms of fault mirror formation and fault healing in carbonate rocks. Earth and Planetary Science Letters, 530, 115886. https://doi.org/10.1016/j.epsl.2019.115886

Papachristou, M., Voudouris, K., Karakatsanis, S., D'Alessandro, W., \& Kyriakopoulos, K. (2014). Geological setting, geothermal conditions and hydrochemistry of south and southeastern Aegean geothermal systems. In A. Baba, J. Bundschuh, \& D. Chandrasekharam (Eds.), Geothermal systems and energy resources: Turkey and Greece (Vol. 1, pp. 47-75). Boca Raton, FL: CRC Press.

Papoulis, D., Romiou, D., Kokkalas, S., \& Lampropoulou, P. (2013). Clay minerals from the Arkitsa fault gouge zone, in Central Greece, and implications for fluid flow. Bulletin of the Geological Society of Greece, 47(2), 616-624. https://doi.org/10.12681/bgsg.11095

Pieri, M., Burlini, L., Kunze, K., Stretton, I., \& Olgaard, D. L. (2001). Rheological and microstructural evolution of Carrara marble with high shear strain: Results from high-temperature torsion experiments. Journal of Structural Geology, 23(9), 1393-1413. https://doi. org/10.1016/s0191-8141(01)00006-2

Platt, J. P., \& De Bresser, J. H. P. (2017). Stress dependence of microstructures in experimentally deformed calcite. Journal of Structural Geology, 105, 80-87. https://doi.org/10.1016/j.jsg.2017.10.012

Power, W. L., \& Tullis, T. E. (1989). The relationship between slickenside surfaces in fine-grained quartz and the seismic cycle. Journal of Structural Geology, 11(7), 879-893. https://doi.org/10.1016/0191-8141(89)90105-3

Pozzi, G., De Paola, N., Holdsworth, R. E., Bowen, L., Nielsen, S. B., \& Dempsey, E. D. (2019). Coseismic ultramylonites: An investigation of nanoscale viscous flow and fault weakening during seismic slip. Earth and Planetary Science Letters, 516, 164-175. https://doi. org/10.1016/j.epsl.2019.03.042

Rauch, E. F., \& Véron, M. (2014). Automated crystal orientation and phase mapping in TEM. Materials Characterization, 98, 1-9. https:// doi.org/10.1016/j.matchar.2014.08.010

Renner, J., Evans, B., \& Siddiqi, G. (2002). Dislocation creep of calcite. Journal of Geophysical Research, 107(B12), 2364. https://doi. org/10.1029/2001JB001680

Rice, J. R. (2006). Heating and weakening of faults during earthquake slip. Journal of Geophysical Research, 111, B05311. https://doi. org/10.1029/2005JB004006

Rutter, E. H., Casey, M., \& Burlini, L. (1994). Preferred crystallographic orientation development during the plastic and superplastic flow of calcite rocks. Journal of Structural Geology, 16(10), 1431-1446. https://doi.org/10.1016/0191-8141(94)90007-8

Sammis, C., King, G., \& Biegel, R. (1987). The kinematics of gouge deformation. Pure and Applied Geophysics, 125(5), 777-812. https:// doi.org/10.1007/BF00878033

Sammis, C. G., \& Ben-Zion, Y. (2008). Mechanics of grain-size reduction in fault zones. Journal of Geophysical Research, 113 , B02306. https://doi.org/10.1029/2006JB004892

Sammis, C. G., Osborne, R. H., Anderson, J. L., Banerdt, M., \& White, P. (1986). Self-similar cataclasis in the formation of fault gouge. Pure and Applied Geophysics, 124(1-2), 53-78. https://doi.org/10.1007/BF00875719 
Schmid, S. M., Boland, J. N., \& Paterson, M. S. (1977). Superplastic flow in finegrained limestone. Tectonophysics, 43(3-4), 257-291. https:// doi.org/10.1016/0040-1951(77)90120-2

Scholz, C. H. (1988). The brittle-plastic transition and the depth of seismic faulting. Geologische Rundschau, 77(7), 319-328. https://doi. org/10.1007/BF01848693

Scholz, C. H. (1998). Earthquakes and friction laws. Nature, 391, 37-42. https://doi.org/10.1038/34097

Sibson, R. (1982). Fault zone models, heat flow, and the depth distribution of earthquakes in the continental crust of the United States. Bulletin of the Seismological Society of America, 72(1), 151-163.

Smith, S., Di Toro, G., Kim, S., Ree, J., Nielsen, S., Billi, A., \& Spiess, R. (2013). Coseismic recrystallization during shallow earthquake slip. Geology, 41, 63-66. https://doi.org/10.1130/g33588.1

Stipp, M., Stünitz, H., Heilbronner, R., \& Schmid, S. M. (2002). The eastern Tonale fault zone: A "natural laboratory" for crystal-plastic deformation of quartz over a temperature range from 250 to $700^{\circ} \mathrm{C}$. Journal of Structural Geology, 24(12), 1861-1884. https://doi. org/10.1016/s0191-8141(02)00035-4

Thomson, S. N., Stöckhert, B., \& Brix, M. R. (1998). Thermochronology of the high-pressure metamorphic rocks of Crete, Greece: Implications for the speed of tectonic processes. Geology, 26(3), 259-262. https://doi.org/10.1130/0091-7613(1998)026<0259:TOTHPM>2.3.CO;2

Tokle, L., Hirth, G., \& Behr, W. M. (2019). Flow laws and fabric transitions in wet quartzite. Earth and Planetary Science Letters, 505, 152-161. https://doi.org/10.1016/j.epsl.2018.10.017

Toy, V. G., Mitchell, T. M., Druiventak, A., \& Wirth, R. (2015). Crystallographic preferred orientations may develop in nanocrystalline materials on fault planes due to surface energy interactions. Geochemistry, Geophysics, Geosystems, 16, 2549-2563. https://doi. org/10.1002/2015GC005857

Trepmann, C. A., Hsu, C., Hentschel, F., Döhler, K., Schneider, C., \& Wichmann, V. (2017). Recrystallization of quartz after low-temperature plasticity-The record of stress relaxation below the seismogenic zone. Journal of Structural Geology, 95, 77-92. https://doi org/10.1016/j.jsg.2016.12.004

Trepmann, C. A., \& Stöckhert, B. (2013). Short-wavelength undulatory extinction in quartz recording coseismic deformation in the middle crust-An experimental study. Solid Earth, 4, 263. https://doi.org/10.5194/se-4-263-2013

Verberne, B. A., de Bresser, J. H., Niemeijer, A. R., Spiers, C. J., de Winter, D. M., \& Plümper, O. (2013). Nanocrystalline slip zones in calcite fault gouge show intense crystallographic preferred orientation: Crystal plasticity at sub-seismic slip rates at $18-150{ }^{\circ} \mathrm{C}$. Geology, 41 , 863-866. https://doi.org/10.1130/g34279.1

Verberne, B. A., Niemeijer, A. R., De Bresser, J. H., \& Spiers, C. J. (2015). Mechanical behavior and microstructure of simulated calcite fault gouge sheared at $20-600^{\circ} \mathrm{C}$ : Implications for natural faults in limestones. Journal of Geophysical Research: Solid Earth, 120, 8169-8196. https://doi.org/10.1002/2015JB012292

Verberne, B. A., Plümper, O., \& Spiers, C. J. (2019). Nanocrystalline principal slip zones and their role in controlling crustal fault rheology. Minerals, 9(6), 328. https://doi.org/10.3390/min 9060328

Violay, M., Nielsen, S., Gibert, B., Spagnuolo, E., Cavallo, A., Azais, P., et al. (2014). Effect of water on the frictional behavior of cohesive rocks during earthquakes. Geology, 42, 27-30. https://doi.org/10.1130/G34916.1

Walker, A. N., Rutter, E. H., \& Brodie, K. H. (1990). Experimental study of grain-size sensitive flow of synthetic, hot-pressed calcite rocks Geological Society, London, Special Publications, 54(1), 259-284. https://doi.org/10.1144/gsl.sp.1990.054.01.24 